\title{
Symbiosis and the Anthropocene
}

\author{
Erik F. Y. Hom ${ }^{1}$ (D) $\cdot$ Alexandra S. Penn ${ }^{2}$ (I) \\ Received: 20 April 2021 / Accepted: 6 July 2021 / Published online: 3 September 2021 \\ (C) The Author(s) 2021
}

\begin{abstract}
Recent human activity has profoundly transformed Earth biomes on a scale and at rates that are unprecedented. Given the central role of symbioses in ecosystem processes, functions, and services throughout the Earth biosphere, the impacts of human-driven change on symbioses are critical to understand. Symbioses are not merely collections of organisms, but co-evolved partners that arise from the synergistic combination and action of different genetic programs. They function with varying degrees of permanence and selection as emergent units with substantial potential for combinatorial and evolutionary innovation in both structure and function. Following an articulation of operational definitions of symbiosis and related concepts and characteristics of the Anthropocene, we outline a basic typology of anthropogenic change (AC) and a conceptual framework for how AC might mechanistically impact symbioses with select case examples to highlight our perspective. We discuss surprising connections between symbiosis and the Anthropocene, suggesting ways in which new symbioses could arise due to AC, how symbioses could be agents of ecosystem change, and how symbioses, broadly defined, of humans and "farmed" organisms may have launched the Anthropocene. We conclude with reflections on the robustness of symbioses to AC and our perspective on the importance of symbioses as ecosystem keystones and the need to tackle anthropogenic challenges as wise and humble stewards embedded within the system.
\end{abstract}

Keywords Coevolution $\cdot$ Anthropogenic change $\cdot$ Climate change $\cdot$ Symbiogenesis $\cdot$ Invasive species $\cdot$ Farming $\cdot$ Agriculture . Fermented foods · Robustness - Homeostasis - Wicked problems · Biodiversity

\section{Introduction}

Symbiosis is an important mechanism for generating biological novelty, shaping biodiversity, and driving major transitions on Earth (Maynard Smith 1989; Margulis and Fester 1991; Szathmáry and Maynard Smith 1995; Maynard Smith and Szathmary 1997; Szathmáry 2015). Symbiotic systems have demonstrated practical importance for ecosystem functions, biogeochemical cycles (Wang et al. 2007; Beinart 2019), and ecosystem services that include those important for agriculture (e.g., symbiotic nitrogen fixation (Bohlool et al. 1992; Peoples et al. 2009)), soil structure and water retention (e.g., biological soil crusts (Pietrasiak et al. 2013)),

Erik F. Y. Hom

erik@fyhom.com

1 Department of Biology and Center for Biodiversity and Conservation Research, University of Mississippi, University, MS 38677, USA

2 Department of Sociology and Centre for Evaluation of Complexity Across the Nexus, University of Surrey, Guildford, Surrey GU2 $7 \mathrm{XH}, \mathrm{UK}$ woodland and forest health (e.g., trees with arbuscular mycorrhizal fungi (Bonfante and Genre 2010; Willis et al. 2013)), human and animal health (e.g., gut/rumen microbiomes (McFall-Ngai et al. 2013; McFall-Ngai 2014)), and sustaining biodiversity (e.g., coral reef ecosystems (Blackall et al. 2015)). Symbioses and the services they provide have been essential for human society. In return, how has human society impacted these symbioses and the landscape of symbiosis in general?

The global COVID-19 pandemic has starkly revealed both the influences of human agency on ecosystems and the extent of potential consequences for society (Dinerstein et al. 2020; Rutz et al. 2020; Buck and Weinstein 2020; Ibn-Mohammed et al. 2021). Human impacts on the biosphere are widely accepted to be of such magnitude that we may have moved into a new geological era, the "Anthropocene" (Crutzen 2016), in which large scale drivers of environmental change stem from human activity (Ruddiman 2013; Lewis and Maslin 2015; Steffen et al. 2015a, 2020; Sarrazin and Lecomte 2016). These changes, which include climate change, pollution, habitat destruction, biodiversity loss, disruption of microbial processes, and an increase in invasive species, can have dramatic 
and widespread effects on evolutionary and ecological dynamics in the wild (Alberti 2015; Cheptou et al. 2017; Pelletier and Coltman 2018; Cavicchioli et al. 2019). The impact of these anthropogenic changes on symbiotic associations and on the formation of new symbioses is an open question gaining increasing attention (Six et al. 2011; Johnson et al. 2013; Mayer et al. 2014; Redman and Rodriguez 2017; Baker et al. 2018; Steidinger et al. 2019; Allgeier et al. 2020; Shu et al. 2020).

Given the degree of anthropogenic change (AC) that we have been witnessing along with its incontrovertible impact on iconic symbiotic systems such as corals (Vitousek et al. 1997; Hughes et al. 2017), it is pertinent to ask whether, how, and why symbioses (as opposed to other more general ecological relationships or organisms as individuals) might be particularly or differently affected by AC. We believe it is most useful to consider symbioses as constituting complex networks of relationships combining both biotic and abiotic components (for example, the chemical environment immediately around the symbionts; see Section 2 for details). Symbioses may be more fragile to AC via its impact on any of these critical relationships or multiple simultaneous aspects of the symbiotic system. Conversely, the existence within symbioses of active or homeostatic mechanisms to re-create and reconstitute these relationships may imbue a degree of resilience and environmental buffering against AC. At least several questions follow from this line of rationale: under what conditions does symbiotic association (as a life strategy) lead to improved resilience? How evolvable are symbioses? To what degree are symbiotic associations permanent and irreversible (Doolittle et al. 2014)? Which sorts of $\mathrm{AC}$ in particular could impact symbioses negatively? Is AC always destructive-i.e., are there certain human activities that could positively sustain or facilitate new symbiotic associations? Answers to these questions will likely entail many in-depth case studies and many more years of research. Our goal in this piece is to offer a perspective on how we might begin to approach these questions systematically, viewing AC and symbiosis through a common lens.

\section{Symbiosis in light of ecology and evolution}

\subsection{An operational definition of symbiosis}

Central to understanding the impact of anthropogenic change on symbioses is a clear definition of terms. Symbiosis, as we define it, is the shared genetic fate of two or more organisms via physical association. This physical association establishes a spatiotemporal co-localization that imposes shared selective pressures for co-evolution, reduces the number of interactions with others (e.g., via endosymbiosis or by simple physical exclusion; cf. (Crowder and Cooper 1982; Stachowicz
2001)), and increases the reliability of repeated partner interactions that can bootstrap further co-evolution. We espouse two further conditions that we believe are important in defining symbiosis from an evolutionary ecology perspective; symbiotic partners: (1) must share an environment that may be uniquely co-created, and (2) do so for a significant portion of at least one partner's life cycle (sufficient for common selection pressures to be experienced by all partners).

In our view, terms like "mutualism," "commensalism," and "parasitism" are fraught with difficulties: these terms describe a "snap-shot" in time, or "on-average" view, of relationships that may be fluid (Bronstein 1994; Johnson et al. 1997; van Baalen and Jansen 2001; Leung and Poulin 2008; Smith and Smith 2013; Regus et al. 2015; Zug and Hammerstein 2015; Shapiro and Turner 2018) that we believe should be viewed independent of the definition of symbiosis. These relationships are largely perceived with bias by the experimenter and rarely justified by measurements of fitness, which we believe are required for a proper characterization of these relationships. Moreover, simple net-sum cost-benefit analyses may be misleading as there may be a multiplicity of costs and benefits operating at once that mutually mask one another in an environmentally dependent manner (Smith and Smith 2013, 2015; Wagg et al. 2015). Trade-offs are a rule in biology (Csete and Doyle 2002; Tilman 2004; Shoval et al. 2012; Szekely et al. 2013; Cowan et al. 2014; Tilman et al. 2020), and complex trade-offs in a relationship may not be simply reducible to a single scalar value.

Net-sum relationship descriptors like mutualism and parasitism also fail to capture an important facet of partner interaction: the degree of dependence. Descriptors like "obligate" and "facultative" are often used, but these terms often have a "positive benefit" bias in their use that muddies terminology. For example, these terms are used in reference to mutualisms in roughly equal measure, but rarely is this the case for parasitisms - many parasitic stages are obligate, but parasites that might be facultative in their parasitism (causing harm opportunistically) might typically be referred to simply as pathogens (cf. Méthot and Alizon 2014). Obligate/ facultative are rarely if ever used in the context of commensalism, in which there are apparently low costs of association and low partner dependence is assumed. Douglas (2010) has highlighted scenarios of symbiotic "addiction," in which the degree of dependence by one partner is high, but the benefits received are negligible (Douglas 2010; Sullivan 2017). Symbiotic addiction as defined fundamentally requires a coevolutionary trajectory in order to come into being. This underscores the intrinsic problem of discussing symbioses using "instantaneous terms" when a "whole trajectory" framework is needed. We believe it is most helpful and insightful to disentangle discussions of degree of dependence (e.g., low or high) from considerations of fitness costs and/or benefits, and to be mindful of eco-evolutionary timescales. Like 
relationships discussed above that are potentially fluid, the degree of dependence lies on a continuum and can vary over time (Nguyen and van Baalen 2020). Furthermore, partner dependence, fitness costs, and benefits, are all environmentand context-dependent variables, a critical idea that we will discuss below in greater depth vis-à-vis anthropogenic-driven environmental change.

Implicit in discussions about the reversibility of symbioses (often intertwined with the reversibility of cost-benefit relationships as discussed above) is a fundamental notion of degree of integration. Symbioses are unions that must integrate different and redundant aspects, particularly functions, of each individual with its partners. Given a co-evolutionary framework, the degree of partner integration is thus historically contingent and a consequence of selection acting on the emergent symbiotic phenotype (which may be considered to be an "interactor" in evolutionary terms (Booth 2014)). We currently lack a common framework for discussing or quantifying degrees of integration beyond the ideas of genome integration/reduction pioneered particularly by those studying endosymbionts and the evolution of organelles (Ochman and Moran 2001; Moya et al. 2008; McCutcheon and Moran 2011; Bennett and Moran 2015; Keeling and McCutcheon 2017). While genomic changes and metrics are critical descriptors of the degree of symbiotic integration, measures that describe the degree of functional integration would be welcome, especially since some functions may be redundantly encoded by multiple genes (Altenhoff et al. 2012; Das et al. 2016) and some genes may encode for multiple functions (Jeffery 2003; Piatigorsky 2007; Kalsotra and Cooper 2011; Kelemen et al. 2013; Brunet et al. 2018; Chen et al. 2021; Gallaher et al. 2021).

It is our perspective that homeostasis - the process of dynamic readjustment towards maintaining essential system variables that are subject to change - is a vital, emergent property of symbiotic systems that must be at the forefront of our thinking about how AC impacts symbioses. System homeostasis relates directly to our defining condition that symbiotic partners share and co-construct a common environment (see below). How partners actively niche-construct and maintain their symbiotic association determines the extent to which they are resilient and able to buffer against the degree and timescales of environmental change.

\subsection{On the evolution of symbiosis}

Symbiosis, and symbiogenesis (the creation of a new symbiosis) in particular, provides a unique opportunity to study processes at the nexus of ecology and evolution. Symbioses exist in a continuum linking ecological interactions with the origins of higher-level evolutionary units. This forces us to explicitly consider: interspecies interactions between unrelated organisms, aspects of self vs. non-self, interactions of each organism with the abiotic environment, and the inextricable link between biotic and abiotic system components. Our view on how abiotic and biotic factors come into play in the formation of symbioses is depicted in Fig. 1. From the perspective of a single organism, we view its "environment" to be composed of both abiotic (non-living) and biotic (living) components, the latter being a more dynamic (agent-driven) aspect of one's surroundings. At the interface of symbiotic association, what one organism "sees" of the environment fundamentally changes in symbiosis through a shared environment that is co-created and maintained by partners. Asymmetric access to the external environment may be a common feature of symbiotic associations between partners of significantly different sizes, highlighting the degree of partner dominance as another potentially important facet of symbiosis and the possibility of "partner-driven buffering" of the abiotic environment. Endosymbiosis is the most extreme case of this whereby a partner embedded within a "host" is buffered from the external environment through internal host physiology. In the sense of partners co-creating a shared environment, symbioses embody key features of an ecosystem as a system of biotic and abiotic components defined by their mutual interactions as originally proposed by Tansley (Tansley 1935; Blew 1996; Lidicker Jr 2008). System complexity emerges from the linking and co-localization of biotic and shared abiotic niches in space and time. From the point of view of population genetics, this leads to a genotype $\times$ genotype $\times$ environment $(\mathrm{G} \times \mathrm{G} \times \mathrm{E})$ interaction that can co-evolve (Thompson 2005, 2009, 2013, 2014; Morris 2018; Henry et al. 2020).

Symbioses by definition involve a close association and interaction between genetically dissimilar partners, meaning that their very existence as recognizable entities is fundamentally determined by their inter-relationships as portrayed in Fig. 1B. The nature and stability of those inter-relationships are dependent on multiple factors in both their abiotic and biotic contexts - the environment in which each partner is embedded - any of which might be disrupted by anthropogenic change. The relationships between symbiotic partners and the mechanisms evolved to reinforce them could provide a buffer against change: for example, by stabilizing a coconstructed environment or by active mechanisms to sense, find, and connect partners. From an evolutionary perspective, the degree of reliability in "reproducing" (i) a particular set of inter-relationships between partners and their environment, and (ii) the mechanisms in place to recapitulate those interrelationships, is important for determining the extent to which a specific symbiosis constitutes a higher-level evolutionary unit of selection. This prompts us to distinguish a symbiosis from a more general or transient ecological interaction. Although out of the scope of this particular contribution, we refer the reader to several rich discussions about how symbioses or holobionts (i.e., suite of symbiotic partners (Margulis 1991)) might become evolutionary units of selection and be 
A

Fig. 1 Symbiosis connects different organisms with one another through interspecific interactions to experience a common surrounding environment in space and time as well as a unique, interfacial symbiotic niche that they co-create. The perspectives of different organisms vis-àvis the environment converge as they enter into symbiosis through physical association. (A) Each organism that is apart and separated interacts with the environment by itself, as indicated by the diffuse blue/red cloud (with dashed boundary). (B) In symbiosis, each organism comes into sustained and intimate contact so that their 'perspective spheres'

considered as biological individuals at a new, higher level (Margulis 1992; Queller 1997; Maynard Smith and Szathmary 1997; Booth 2014; Gilbert and Tauber 2016; Roughgarden et al. 2018; Rosenberg and Zilber-Rosenberg 2018). Nonetheless, we feel it is critical to emphasize the importance of the temporal dimension in symbiotic interactions. In the "dance" of symbiosis, the rhythms and timescales of partner processes and life cycles must be complementary and sufficiently synchronized for the association to develop and persist. Evolutionary forces will act to shape these rhythms and dynamics of symbiotic association, and how they are shaped may impact how they respond to AC. Our aim in this commentary is to explore the evidence for how symbioses in particular (as opposed to ecological interactions in general) might be affected by $\mathrm{AC}$ and whether general principles or broader inferences can be deduced.

\section{The nature of anthropogenic change (AC)}

\subsection{Characterizing the Anthropocene}

In the periods of time since the origins of agriculture and the beginning of the Industrial Revolution, multiple, large-scale, rapid, and accelerating changes have been observed in the Earth system (Steffen et al. 2007, 2015b, a; McNeill and Engelke 2016). Although the concept of the Anthropocene is still being formalized, the evidence for large and unprecedented human impacts on climate, biogeochemical cycles, biodiversity, habitat and land use change is widely accepted (Rockström et al. 2009; Ellis et al. 2010; IPCC AR5 Synthesis Report 2014; Steffen et al. 2015b), and has framed broad calls for new approaches to economic and societal development (see e.g., UNDP Human Development Report 2020; HM Treasury (UK) 2021). The need to respond to large scale AC is now mainstream and has started to drive policy actions to

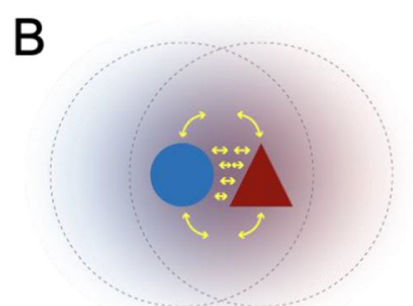

"interfere," creating a unique niche (purple overlap) shared by partners that supplements specific symbiotic interactions that define the association. Yellow arrows indicate interactions of each organism with each other, with the surrounding environment, or with an environment they construct together. Endosymbiosis is a specialized and more extreme union of partners, where the environment of one partner is essentially dictated by the internal environment of another and thus buffered from the external abiotic environment.

curb global megatrends that alter human-biosphere interactions over the coming century (Ribeiro et al. 2012).

Rapidly accelerating changes in both environmental and socio-economic variables are a defining feature of the Anthropocene, and one such set of variables that describe this so-called "Great Acceleration" (Steffen et al. 2015a) is presented in Table 1 . These variables were chosen for their ability to represent the nature of human demands and influence on the Earth system and consequent changes in the structure and function of biogeochemical cycles and biomes.

In addition to these specific variables gauging $\mathrm{AC}$, there has been increasing modification of ecosystems to meet human needs (Ellis et al. 2010; Williams et al. 2015), homogenization of ecological communities (Rosenzweig 2001; Didham et al. 2005), large scale biodiversity loss (Barnosky et al. 2011; Pimm et al. 2014), habitat fragmentation and destruction (Laurance 2010; Betts et al. 2019), and large scale land use change as more of the Earth's surface and primary

Table 1 Accelerating variables that define the Anthropocene (after Steffen et al. 2015a).

\begin{tabular}{ll}
\hline Socioeconomic Trends & Earth System Trends \\
\hline Population & Carbon Dioxide \\
Real GDP & Nitrous Oxide \\
Foreign Direct Investment & Methane \\
Urban Population & Stratospheric Ozone \\
Primary Energy Use & Surface Temperature \\
Fertiliser Consumption & Ocean Acidification \\
Large Dams & Marine Fish Capture \\
Water Use & Shrimp Aquaculture \\
Paper Production & Nitrogen to Coastal Zone \\
Transportation & Tropical Forest Loss \\
Telecommunications & Domesticated Land \\
International Tourism & Terrestrial Biosphere Degradation \\
\hline
\end{tabular}


productivity is brought into human use (Millennium Ecosystem Assessment 2005; Smil 2011). Biodiversity changes have been accompanied by dramatic abiotic changes, including increased fossil fuel use, the synthesis and widespread environmental disposal of new chemical substances, and the reshaping of biogeochemical cycles (Canfield et al. 2010; Steffen et al. 2015a).

While environmental change has occurred throughout the history of life on Earth, many argue that AC merits special consideration as being both qualitatively and quantitatively different from prior change. In particular, anthropogenicallydriven changes are: (i) rapid and potentially accelerating (Steffen et al. 2015a), so that the possibility of evolutionary escape is diminished (Ellis 2019); (ii) simultaneous in occurrence; (iii) large in magnitude relative to pre-existing earth system dynamics (Canfield et al. 2010; Steffen et al. 2015a); (iv) large in spatial scale, so that possibility of adaptation via migration is diminished (Zalasiewicz et al. 2008; Barnosky et al. 2012); and (v) often abrupt and discontinuous due to cascading failure of interconnected systems (Lenton et al. 2008). AC leads to dramatic changes in selective pressures and the availability of potential partners, so symbioses may be profoundly affected. The context-dependency of symbiotic interactions has been well known for years (Daskin and Alford 2012; Hoeksema and Bruna 2015), but a framework for understanding mechanistically how AC may influence this has not been well-formulated.

\subsection{A preliminary typology of AC}

In order to more systematically consider the potential impacts of AC on symbioses, we have synthesized the aspects discussed above into a typology of AC. Given the connectedness and complexity of ecological communities and their environmental interactions, the specific "Anthropocene variables" of Table 1 do not map precisely onto a single specific 'type of change' shown below. There are numerous one-tomany and many-to-one connections, and the concepts below are inherently interdependent. However, we believe that such a typology, alongside a framework for understanding potential impacts on symbioses (Section 4.1), provides a path forward toward disentangling how AC can affect the various evolutionary and ecological aspects of symbioses that are in general distinct from other ecological relationships.

We propose the following ten types of change that can arise from human activity:

\section{Change in existing niches.}

Either the expansion/contraction of existing niches or the creation/destruction of niches can occur (Evers et al. 2018). For example, urbanization has led to increased availability of concrete surfaces and the built environment, and the expansion of developed residential communities has yielded a rise in artificial ponds and lakes at the expense of natural habitats.

\section{Change in homogeneity or heterogeneity of the environment.}

This may be a change in habitat or environmental diversity in space and/or in time. Increased homogeneity could arise due to the creation of new large-scale environments, e.g., as seen associated with industrial agriculture. Conversely, increased heterogeneity may arise due to disturbance-driven fragmentation of habitats.

\section{Change in 'large-scale' abiotic environmental vari- ables, specifically average values.}

A change in the mean value or stable state of global (or higher-level) environmental variables. For example, global temperature, ocean acidification, or widespread microplastic pollution.

\section{Change in 'smaller-scale' abiotic environmental vari- ables, specifically average values.}

This is a more focused change at a local/regional scale that may come about, e.g., through damming, deforestation, or fertilizer use.

\section{Change in the variability of global or local abiotic en- vironmental variables.}

A change in the degree of variation, e.g., wider or more erratic temperature fluctuations, or more extreme precipitation patterns.

\section{Introduction of new, human-synthesized products into the environment.}

This includes new substances and their degree of release into the environment. For example, plastics, antibiotics, organophosphates, herbicides, noise, light, and increasingly, genetically engineered/synthetic organisms (Rhind 2009; Halfwerk and Slabbekoorn 2015; Schmidt and de Lorenzo 2016; Bernhardt et al. 2017; McMahon et al. 2017; Mitchell and Bartsch 2019; Saxena et al. 2020; Häder et al. 2020; Levy et al. 2020). The recent magnitude and frequency of harmful algal blooms due to increased fertilizer run-off into aquatic habitats (Kudela et al. 2015; Griffith and Gobler 2020) is a vivid reminder of this type of AC.

\section{Change in community composition.}


A biodiversity shift in compositional make-up in space or extent (range) and/or in time (Pecl et al. 2017). This may arise from the arrival or disappearance of species, the construction/ management/preservation of new habitats or assemblages (e.g., urban area or farm), or increased anthropogenic mixing of species via active transportation or habitat incursion. This fundamentally alters the distributions of species and consequently their interactions.

\section{Change in interlinkages between system components.}

This captures interlinkages that may form (or disappear) at levels higher than the interaction of individual species. This may occur through decoupling of habitats (e.g., damming or dividing habitats by road/structure construction) or via coupling the previously unconnected (e.g., linking underwater oil reserves to surface waters and beaches in the Deepwater Horizon oil spill (Beyer et al. 2016), air travel linkages that connect pathogen hotspots globally (Tatem et al. 2006; Bell et al. 2021), or maritime transport that facilitates long-range dispersals (Wilson et al. 2009; Blakeslee et al. 2010; Lymperopoulou and Dobbs 2017)).

\section{Change in community "momentum" or trajectory.}

Disruption of successional processes can dramatically alter an ecosystem's momentum or trajectory of development. For example, repeated ploughing in conventional agriculture, clearing in slash-and-burn agriculture, and the monoculture planting of climax perennial tree species in forestry (Thomas and Kevan 1993; Altieri 2002) all interfere with the "flow" of succession and actively alter an ecosystem's trajectory.

\section{Change in selective processes.}

This may occur via "inadvertent" selection from byproducts of AC. For example, coastal urbanization may de facto lead to high light levels that negatively select against coral symbioses sensitive to light pollution (Levy et al. 2020). This may also occur via active and deliberate manipulation of selective processes such as domestication and artificial selection (Ellis et al. 2010; Williams et al. 2015). Prominent in the agricultural realm (in which many symbioses are at play), the results of large-scale artificial selection may profoundly impact symbiotic associations (Porter and Sachs 2020). In agricultural fertilization, artificial selection may occur in conjunction with herbicidal or nutrient supplementation (see \#6 above) to select for specific and sometimes completely new or engineered cultivars (e.g., Bt cotton or glyphosate/ Roundup-ready crops (Raman 2017)).

\section{How anthropogenic change impinges on extant symbioses}

\subsection{A framework for how AC impacts extant symbioses}

Given our perspective presented in Section 2.2 and in Fig. 1, we conceive of 5 major ways in which the types of AC could impact extant symbioses (Fig. 2). Importantly, we have framed this with respect to the external forces of $\mathrm{AC}$ from the point of view of the individual partners involved in the symbiosis (I-III) or the holobiont (IV-V):

(I) AC impacts one or more symbionts directly, specifically altering fitness (i.e., $\mathrm{AC}$ alters individual PARTNER FITNESS)

The fitness of partners could be differentially affected (Fig. 1A) and if significantly decreased, for example, could lead to the collapse of the whole symbiosis.

(II) AC impacts a specific interaction or mode of interaction of symbiotic partners directly (i.e., AC alters the SYMBIOTIC INTERACTION)

Changing the pay-offs of interaction (i.e., costs vs benefits) and/or the consistency of those pay-offs may fundamentally alter a partner relationship (cf. Section 2.1). AC may directly target or interfere with specific modes of partner interaction.

(III) AC impacts the availability of partners/competitors for partner interaction and association (i.e., $\mathrm{AC}$ alters the BIOTIC FILTER)

AC may change the ecological landscape of available partners (who interacts with whom) through simple structural changes in community or population composition.

(IV) AC impacts the fitness or ecological interactions of the symbiotic entity as a whole (i.e., AC alters HOLOBIONT FITNESS]

This can occur by changing either: (i) the niches available to the holobiont, or (ii) the degree or nature of interaction of the holobiont with other biota.

(V) AC impacts the trajectory, rhythms, or dynamics of symbiosis (i.e., AC alters the HOLOBIONT TRAJECTORY) 
Fig. 2 A framework for how AC impacts symbiosis. See main text for description of the 5 targets or modes of alteration. The numbers in square brackets indicate the types of AC (as described in Section 3.2) that may most commonly be mapped onto these 5 targets/modes of impact. The different length arrows in (I) highlight that differential impact on partner fitness is possible. While targets (I) through (IV) are essentially instances of the state of a symbiosis in time, target $(\mathrm{V})$ is focused on an intrinsically timedependent developmental process. The impact of $\mathrm{AC}$ on these targets are never truly independent from one another, but the utility of this framework is in delineating the primary, most proximal points of influence.

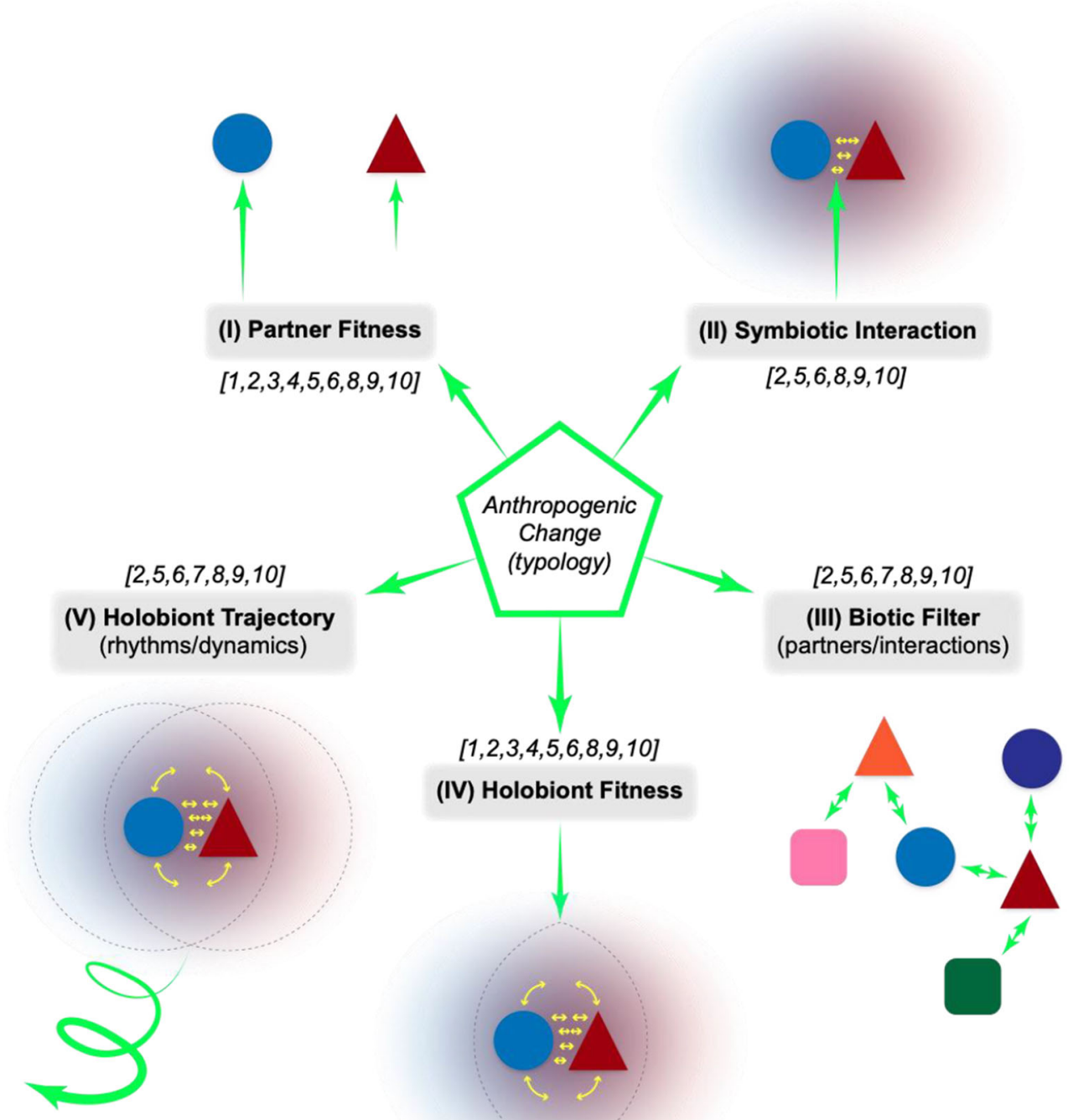

This mode focuses explicitly on the temporal dimension. The developmental and maintenance processes of symbioses are vital for their existence as a recognizable entity, but are distributed between partners, and hence potentially more variable and vulnerable to change. AC may interrupt the dynamics/rhythms of partnership formation or impact holobiont homeostasis, and there may be priority effects depending on when change occurs: disruptions of interactions early in a cascade of feedbacks may have a more profound downstream effect.

\subsection{Framework applied: case examples of how AC impacts extant symbioses}

Given the framework above, we can more systematically delineate specific ways that $\mathrm{AC}$ can affect symbiotic relationships. Below, we provide select, illustrative examples for each mode of impact. Our intent is by no means to be exhaustive, but simply to outline how such a framework could be useful to resolve the links between cause and effect of AC on symbioses and underlying mechanisms. There are likely many other excellent examples that could have been chosen (cf. Secord 2002; Six et al. 2011; Bénard et al. 2020; Apprill 2020) and our hope is that others will be prompted to explore how this framework could be applied to specific systems of interest. As noted in Fig. 1, we consider a general arrangement whereby both symbiotic partners may have direct access to the external environment. Endosymbiosis is a more specialized (if not more extreme) case of partner coupling in which there may be greater integration and partner dependency, as well as a shielding of the endosymbiotic partner from the external environment (cf. Doolittle et al. 2014). Thus, the arrangement of endosymbiosis can limit certain modes of AC impact that we describe below. In general, modes (I)-(III) focus on a partnersas-individuals perspective while modes (IV)-(V) focus on a holobiont-as-unit perspective. 
(I) AC impacts one or more symbiotic partners directly, specifically altering fitness (PARTNER FITNESS)

This mode of impact is common to all ecological interactions and might be the most obvious if not most common way by which symbioses can be impacted: AC directly affects the individual fitness of one or more partners. In the case of endosymbiosis, considerations of the external environment on partner fitness often simply reduce to partners that are in direct contact with and immediately affected by the external environmental variable. In the examples below, the symbioses are sufficiently "permeable" to the perturbing AC such that endosymbiont fitness is negatively impacted.

\section{- Air pollution and photobiont sensitivity in lichens.}

One of the most well-known early examples of anthropogenic impacts on symbioses is found with lichens. Socalled "canaries-in-the-coal-mine" indicator species of regional air pollution (Richardson 1991; Seaward 1992; Conti and Cecchetti 2001; Grube 2010), lichens can be particularly susceptible to air pollutants like sulfur dioxide. Many lichen populations in urban areas worldwide have declined dramatically during periods of high and unregulated air pollution (Seaward 2004), although lichen recolonization is possible following improved air quality (Showman 1997; Ranta 2001; Dorey et al. 2019). This fragility appears to stem from a particular sensitivity of the photobiont to air pollutants (Richardson 1988; Nash III and Gries 2002; Grube 2010).

\section{- $\quad$ Thermal stress and photobiont sensitivity in corals.}

Although coral bleaching can involve a complex cascade of events and multifactorial triggers (Weis 2008; Lesser 2011; Davy et al. 2012; Hoegh-Guldberg et al. 2017; Oakley and Davy 2018), coral photobionts (symbiotic dinoflagellates) can be especially and differentially vulnerable to thermal stress (Weis 2010; Howells et al. 2012; Tolleter et al. 2013). Nevertheless, it remains unclear whether and how the coral host or photobionts could be the 'weak link' vis-à-vis many other ecosystem variables that may underlie the failure of the coral symbiosis in response to thermal stress (Hoadley et al. 2019; Suggett and Smith 2020; Drury 2020; Howe-Kerr et al. 2020; McClanahan et al. 2020).

(II) AC impacts a specific interaction or mode of interaction of symbiotic partners directly (SYMBIOTIC INTERACTION)

AC may directly interfere with the very nature of a symbiotic interaction in modifying the pay-off structure of association. Practically, this may be difficult to determine since this requires a careful accounting of costs and benefits to fitness and potentially a mechanistic understanding of how a symbiosis works. For example, if a symbiosis is fundamentally determined by the exchange or recognition of a specific compound $\mathrm{X}$, and $\mathrm{AC}$ leads to a change in the environmental levels of $\mathrm{X}$, this may directly interfere with the "currency" of interaction (cf. Wein et al. 2019) or with symbiotic signaling.

- Nitrogen fertilizers, pollutants, and the disruption of the rhizobial-legume symbiosis.

Legumes derive biologically accessible nitrogen from symbiosis with $\mathrm{N}_{2}$-fixing rhizobia, particularly in nitrogen poor soils. With increased agricultural deposition of nitrogen fertilizers that "inflate" the availability of soil nitrogen (Vitousek et al. 1997), the benefits of rhizobial nodulation of legumes can be greatly diminished with a concomitant deterioration of this symbiosis (Regus et al. 2017; Porter and Sachs 2020). In this case, anthropogenic nitrogen-supplementation selects against the rhizobiallegume association, shifting a symbiotic dependence of crop plants to humans to a point to which some can no longer form symbioses with rhizobia (Porter and Sachs 2020). Organochlorine pesticides, polycyclic aromatic hydrocarbons, polychlorinated biphenyls, and other chemical pollutants have also been shown to disrupt phytohormone-based signaling and recruitment of rhizobia by leguminous host plants (Fox 2004, 2005; Fox et al. 2007) (cf. mode (V) below). It would not be surprising if other symbioses in aquatic habitats are also negatively affected by exposure to such chemical contaminants.

\section{(III) AC impacts the availability of partners/competitors for partner interaction and association (BIOTIC FILTER)}

Another dominant mode by which AC may impact symbioses (and indeed all ecological interactions) from the point of view of individual partners is by altering the larger biotic context. This is a change in community composition or the array of organisms with which a partner could potentially interact.

- Elevated $\mathrm{CO}_{2}$ leads to shifts in plant-microbe community composition.

Plant-associated microbiomes play a critical role in the response of plants to AC and AC can modify plant-microbe associations. Elevated $\mathrm{CO}_{2}$ levels largely correlate with a greater abundance of arbuscular and ectomycorrhizal fungi in soil (Compant et al. 2010) and shifts in rhizosphere microbial communities that can alter the landscape of plant competition and community structure (Drigo et al. 2010; Jo et al. 2019). Elevated $\mathrm{CO}_{2}$ can cause partner plants to release more, 
if not different plant exudate compounds that may increase the competition among rhizosphere microbes and modify the recruitment of specific nitrogen-fixing rhizobial partners (Haase et al. 2007; Sanz-Saez et al. 2019; Prescott et al. 2020).

\section{- Elevated temperature alters available partners in an insect-fungus symbiosis.}

The spectrum of symbiotic fungal partners available to several species of insect hosts can be altered by rising temperatures. In beetle-fungus symbioses, higher temperatures select for warm-acclimated fungal partners over cool-acclimated fungi (Six et al. 2011; Addison et al. 2015; Moore and Six 2015). Warmer temperatures may also alter the ecological landscape of insect hosts indirectly through the volatile compounds produced by warm-tolerant fungal partners that attract parasitoid wasps (Adams and Six 2008; Boone et al. 2008; Six et al. 2011; Addison et al. 2015; Moore and Six 2015). As temperature plays a critical role in mound-building activities of African Macrotermes termites and the species of Termitomyces fungi with which they associate (RoulandLefèvre and Bignell 2002; Vesala et al. 2019), global warming may shift the spectrum of available fungal partners.

\section{- Agriculture and intentional plant-microbe inoculations.}

Crop plants are dependent on the availability of bacterial and fungal symbionts acquired from the soil in which they are planted. In agriculture, tillage regimes can significantly change the symbiont community composition, reducing the ability of crop plants to find symbiotic partners such as arbuscular mycorrhizal fungi (see e.g., Jansa et al. 2003; Kabir 2005). Conversely and often in response, these soils are often amended with specific biotic (microbial inoculants) or abiotic additions that can shift the availability of strains that can partner with plants more or less efficiently, or with different degrees of long-term stability (Vázquez et al. 2000; Bender et al. 2016; Liu et al. 2020).

\section{(IV) AC impacts the fitness or ecological interactions of the symbiotic entity as a whole (HOLOBIONT FITNESS)}

This mode focuses on the symbiotic entity as a whole, and how AC impacts the fitness of the holobiont specifically. AC may alter: (i) the niche space or (ii) ecological interactions available to the holobiont as a selectable unit.

\section{(i) Lichens on gravestones and beneath stained-glass windows-new niches.}

We discussed in relation to mode (I) above how the consequences of human activity, in the form of air pollution, can negatively impact the lichen symbiosis. However, there have also been positive effects of human activity on lichen populations: cemetery gravestones and the leaded windows of churches provided new niches that have spurred the range expansion of diverse lichens (Nash 1989; Seaward 1992, 2004; Purvis and Halls 1996). Lichens colonize gravestone substrates and the areas below stained-glass windows as a result of a confluence of abilities as a holobiont to uniquely occupy these niches: they can attach to stoney substrates, grow photosynthetically, tolerate a range of abiotic stress (e.g., desiccation and UV radiation), and tolerate heavy metal exposure (Backer and Fahselr 2008; Expósito et al. 2020). Lichens grow slowly, but given the very poor fitness of many other biota in these niches, there is apparently little competition or selection for faster growth.

(ii) Holobiont ecology: lichens, biocrusts, and ectomycorrhizal-pine invasions.

As a holobiont, lichens serve as a unique food source for grazing deer and caribou, particularly during the winter in northern subarctic forests (Arseneault et al. 1997; Kumpula 2001; Joly et al. 2010). Human introduction and release of these animals in land management efforts have had a profound impact on lichen populations (den Herder et al. 2003; Joly et al. 2009; Klein and Shulski 2011). Biological soil crusts are symbiotic aggregates of fungal and cyanobacterial/algal communities that contribute vital ecosystem services in dryland habitats, including erosion control, soil water retention, and soil nutrient amelioration (Maestre et al. 2013; Pietrasiak 2014; Bowker et al. 2018; Rodríguez-Caballero et al. 2018; Rossi 2020). Biocrust holobionts can be severely disrupted by physical disturbance caused by human foot-traffic or vehicle off-roading. Lastly, human agency in dispersal, intentional species introductions, and management efforts have resulted in not just invasive species, but invasive assemblages that thrive in non-native environments. This is well exemplified by the co-introduction of the pine tree and symbiotic ectomycorrhizal fungi, which as a holobiont is more fit in exotic pine habitats than in native habitats (Richardson et al. 2000; Secord 2002; Policelli et al. 2019; Hoeksema et al. 2020).

\section{(V) AC impacts the trajectory, rhythms, or dynamics of symbiosis (HOLOBIONT TRAJECTORY)}

Although not explicit, modes (I-IV) above largely consider the action of $\mathrm{AC}$ in the context of a particular instance in time. However, similar to the discussion above (Section 2.1) on the problems with "instantaneous" or average descriptors of symbiosis, it is important to consider the impact of AC on symbiosis from a "whole trajectory" viewpoint. As symbioses are emergent adaptive systems, disruptions at different points 
along the formation and developmental timeline of a symbiosis may have disproportionate effects on the persistence and evolutionary trajectory of the symbiosis (cf. Hammond et al. 2020). The examples below highlight how AC disruptions of homeostatic mechanisms or of developmental/life-cycle rhythms can alter the trajectory of symbiosis.

\section{- Homeostasis and dysbiosis in coral reefs.}

Coral reef ecosystems have homeostatic mechanisms that counter shifts in environmental conditions. However, these can be overwhelmed beyond a tipping point in a non-linear fashion due to inherent feedback loops (Ravindran 2016) in response to AC such as elevated ocean temperatures; this leads to coral bleaching (Weis 2008, 2010) and disease susceptibility (Bruno et al. 2007; Merselis et al. 2018). Even if symbiotic collapse does not occur, significant community compositional shifts may lead to dysbiosis (Egan and Gardiner 2016; Apprill 2017) or alternative states with different partner interrelationships and degrees of dependence that fundamentally alter the future trajectory of the symbiosis (Putnam et al. 2017; Baker et al. 2018; Allgeier et al. 2020). For example, reduced herbivory due to overfishing may be fundamentally responsible for the shift of some coral reef communities from being coral to macroalgal dominated thus impacting the relative composition of coralline algae that play a foundational role in the coral symbiosis (Holbrook et al. 2016). Anthropogenic nutrient enrichment can also profoundly rewire coral-symbiont relationships to increase holobiont susceptibility to other stressors (Allgeier et al. 2020).

\section{- Timing of perturbation on symbiotic development and persistence.}

Holobiont sensitivity to AC is very unlikely to be constant over the life cycle of a symbiosis: timing matters. For example, if AC causes the disruption of active mechanisms of symbiotic partners to find each early on or in the call-and-response nature of symbiotic formation (cf. Clear and Hom 2019; Chiu and Paszkowski 2020), it may be hard if not impossible for the symbiosis to be established. Symbioses between partners with biological rhythms may also be prone to having their holobiont trajectories altered by AC. Anthropogenic disturbance of natural daily, lunar, or annual life cycles (e.g., due to artificial light pollution at night) may lead to shifts in coral holobiont evolutionary trajectories (Rosenberg et al. 2019; Ayalon et al. 2019; Levy et al. 2020). This may occur by impacting important processes of reproduction and recruitment (Richmond et al. 2018; Ayalon et al. 2021).

\section{Symbiogenesis as a consequence and cause of anthropogenic change}

We have thus far focused largely on the negative consequences of anthropogenic change on long-established symbioses. However, there may also be positive consequences: AC has the potential to bring about rapid symbiogenesis; novel symbioses (broadly considered) in turn have the potential to cause large-scale environmental change.

Studying natural ecosystems in light of how they might be negatively impacted by AC as an "external force" implicitly assumes that human activity can be decoupled from natural systems. In the Anthropocene, however, in which few ecosystems on Earth can be considered to be untouched by human agency (Plumptre et al. 2021), this assumption may no longer be useful. We must pivot to viewing and understanding neobiota - novel community arrangements and humanaffected ecosystems-as the norm (Ellis et al. 2010; Williams et al. 2015). Moreover, rather than viewing symbioses simply as entities subject to AC, we should consider symbioses as potentially powerful agents of ecosystem change. Understanding symbiosis with this new perspective will require further work. We discuss several illustrative examples that emphasize this alternative viewpoint.

\subsection{Can AC bring about symbiogenesis?}

We envision 3 ways in which AC could facilitate the birth of new symbioses: (1) through the creation of novel niches, (2) through the introduction of new partners, and (3) through the formation of new relationships and selection regimes. None of these are mutually exclusive and in fact, symbiogenesis may capitalize on a combination of these 3 schemes. In all schemes, serendipitous complementarity of 'accidental' partners may lead to new and unexpected unions on timescales that may be equally rapid as those of AC.

\subsubsection{New niches for occupancy and for new symbioses to be birthed}

AC drives many unprecedented environmental changes that are also opportunities for life to adapt and assemble in new ways. As highlighted in Section 4.2.(IV), symbiotic holobionts may have higher fitness in new niches created by intentional human construction or unintentional anthropogenic mixing. Novel niches provide new opportunities for ecological interactions and partnerships, which may be exploited by new partner pairings. Importantly, these partnerships and potential symbioses may emerge quite quickly without extensive co-evolutionary adaptation, a theme emphasized, for example, by the creation of apparently novel fungal-algal symbioses in the laboratory by engineering environmental conditions conducive for these symbioses to be realized (Aanen and 
Bisseling 2014; Hom and Murray 2014). The exploitation of new, anthropogenically-driven niches is well demonstrated by the rise of invasive species (Seebens et al. 2017, 2020). In a similar way, new symbioses could form (or be strengthened) through "symbiotic invasions" that exploit new niches (cf. Zhao et al. 2013; Lu et al. 2016; Rassati et al. 2019; Hoeksema et al. 2020). Thus, symbioses should be regarded as important ecological entities if not potential keystones of emerging communities in AC-transformed ecosystems (Lanner 1996; Richardson et al. 2000; Secord 2002; Policelli et al. 2019).

$\mathrm{AC}$ can lead to a fundamental shift and conversion of one biome type to another (Foley et al. 2005; Hansen et al. 2013; Hill and Southworth 2016; Watson et al. 2016). For example, increased water demands in agriculture together with global climate change are driving increased desertification of land world-wide (Stringer 2008; Reed and Stringer 2016; Huang et al. 2020). This may open up new habitats for range expansion by desert-favoring symbiotic assemblages like biological soil crusts, which may have an opportunity to colonize. Such new anthropogenically-driven drylands may have their own unique niche characteristics, however, that may select for only specific types of biocrusts (Reed et al. 2016; Steven et al. 2017), or entirely new communities as discussed above (see also Section 5.1.3 below).

\subsubsection{New partners available for symbiogenesis}

Anthropogenic mixing (AM) is a key feature of the Anthropocene. Human mediated dispersal and introduction of foreign species to new areas is an expected consequence of the increased volume and variety of modes of transportation today. Janzen's concept of ecological fitting to explain ecological interactions (Janzen 1980, 1985) applies well here to highlight the potential for new symbioses forming through AM. Ecological fitting can be defined as "the process whereby organisms colonize and persist in novel environments, use novel resources or form novel associations with other species as a result of the suites of traits that they carry at the time they encounter the novel condition" (Agosta and Klemens 2008).

Just as new niche construction may be intentional or unintentional, the pairing of new partners and symbiogenesis can be intentional or unintentional through AM. Laboratory experiments have yielded new symbioses (de-Bashan et al. 2016/4; Jeon and Lorch 1967; Kawabata et al. 1995; Jeon 1995; Kubo et al. 2013; Hom and Murray 2014; Du et al. 2019) and the formation of others may be forthcoming as the field of synthetic ecology grows (Dunham 2007; Grosskopf and Soyer 2014; Kazamia et al. 2014; Song et al. 2014; Zomorrodi and Segrè 2016; Friedman et al. 2017; Cavaliere et al. 2017; Lozano et al. 2019; Kehe et al. 2019; Libby et al. 2019; Mickalide and Kuehn 2019; Hosoda et al. 2020). Agricultural practices to inoculate seeds with 'probiotic' cocktails of microbes (O'Callaghan 2016; Rocha et al. 2019) could very well result in novel crop-microbe associations that persist in the soil sufficiently long for coevolution to occur, although this is rarely if ever investigated to our knowledge. Conceivably, such co-evolution could be facilitated by artificial selection under low- to no-till conditions (cf. Coleman-Derr and Tringe 2014), which is a growing practice today advocated for sustainability reasons (Köhl et al. 2014; Cooper et al. 2016). With synthetic biology methods more commonly deployed to harness or re-engineer nature (for example, the cosmopolitan insect endosymbiont bacterium Wolbachia in gene-drive efforts (Wedell et al. 2019; Champer et al. 2020; Carballar-Lejarazú et al. 2020)), unexpected partnerships/symbioses may follow despite intentions and efforts for biocontainment (Lee et al. 2018; Gronvall 2019; Asin-Garcia et al. 2020; Devos et al. 2020).

The rise of new zoonotic diseases as a consequence of AC is well documented (Gottdenker et al. 2014; Han et al. 2016; Gibb et al. 2020) and the birth of new infectious diseases will correlate with the creation of new "parasitic" symbioses. The COVID-19 pandemic has reminded us that the transmission of new human pathogens is greatly facilitated by travel/trade/AM, so much so that in a short amount of time, the SARS-CoV2 virus is on the verge of becoming endemic like influenza (Phillips 2021; Torjesen 2021). Should endemism result, it could be argued that a new virus-human symbiosis has been established. Not all of these virus-human symbioses may be "doom-and-gloom" in nature, however; as more viruses are discovered, new mutualistic viral symbioses may be revealed as well (Roossinck 2015; Roossinck and Bazán 2017).

\subsubsection{New relationships and selection regimes}

In addition to new partners, $\mathrm{AC}$ can alter conditions that shift relationships and fundamentally change selection regimes. As discussed in Section 2.1, ecological relationships and pay-off structures of symbioses (or proto-symbioses) can change depending on environmental context, making new metabolic interactions and symbiotic complementarity possible. AC may also impose new selection pressures that favor symbiosis (with physical association) and/or a higher degree of interdependency (cf. Hom and Murray 2014; Gillman 2018).

Human farming, discussed in much greater depth below, may be an archetype for how new relationships and selection regimes have been forged through human agency. In the creation of farms and farming practices, new persistent relationships between humans, crop plants, microbes, invertebrates (e.g., worms, pollinators), and livestock animals have been established and carefully groomed by persistent artificial selection. This has led to both an intimate, proximal/physical co-localization of 
genetic lineages as well as a deeply interdependent and co-evolving web of interactions between these lineages within the farm ecosystem.

\subsection{Symbiosis sensu lato: human cultivated systems as novel symbioses?}

\subsubsection{On farming}

In Section 4.2, we discussed the impact of AC on some classic examples of symbioses. More broadly, we think it is intriguing and fruitful to consider what other human-created or manipulated systems could be thought of as "symbioses" under the definition articulated in Section 2.1. Human farming systems are an obvious candidate and as discussed later in this section, have profound connections to the Anthropocene. As discussed above, intensive agricultural practices, including the use of selective breeding and artificial fertilizers, have diminished the ability of rhizobia to form beneficial symbioses with crop plants (Porter and Sachs 2020). While some might view this as just another example of the negative impacts of $\mathrm{AC}$ on an ancient symbiosis, we favor an alternative (if not provocative) perspective that the essence of this crop plant-nitrogen provisioning symbiosis remains functionally the same but with a change in partners: humans have replaced rhizobial symbionts in providing crop plants with nitrogen. This perspective poses a bigger question of whether "farming," when viewed through the lens of persistent relationships that satisfy complementary functions, could be considered a type of symbiosis between humans and specific crops/animals. Our discussion below is framed with the term "farming" as referring to both terrestrial (agricultural) and aquatic (aquacultural) systems, although the majority of examples and focus in the literature (and thus references cited) are of the former.

A number of social and sub-social (i.e., proto-social) insects practice forms of agriculture in which fungal gardens are created, tended, and provide food for their colonies or broods (see Mueller et al. 2005 for a review). This includes the well-known leaf cutter and other attine ants, but also species of termites and ambrosia beetles. These are all longstanding and tightly coupled mutualistic co-evolutionary relationships, commonly described as symbioses. Although human and insect farming are of course different systems, we discuss both below in relation to our definitional criteria for symbiosis. Could human farming, a paragon of sustained $A C$, be reasonably considered a type of symbiotic association?

\section{Physical association and a shared environment in farming In} both insect and human farming, one partner constructs and maintains elaborate environments suited to the other cultivated species (Schultz et al. 2005). Both abiotic and biotic aspects of the environment are controlled. Insect farmers create and manage specific habitats for their fungal cultivars, such as chambers within ant and termite nests or networks of tunnels within trees in the case of ambrosia beetles (Mueller et al. 2005). These constructs both buffer against variations of the external environment and reduce potential interactions between the cultivated fungus and other predators or windborne pathogens. In many cases, cultivars are provided with special high-value substrates, such as the freshly-cut leaves provided by leaf cutter ants (Benckiser 2010; Hölldobler and Wilson 2010). Humans likewise create specific environments to nurture their crops and livestock, clearing land, ploughing, and fertilizing to encourage crop growth. Farming practices have profoundly altered the environment surrounding human societies, the shape and functions of human society, and human biology itself (see below) (Roosevelt 1984; Larsen 1995; Redman 1999; Bellwood 2004; Lambert 2009; Fitzpatrick 2020). Net positive resource outputs from farming have led to the development of complex constructed environments so that farming is believed to be the reason that human settlements formed, resulting in a shift from the nomadic huntergatherer lifestyle (Bellwood 2004; Weisdorf 2005; Thompson et al. 2020; Fitzpatrick 2020). Although most humans and specific domesticated lineages are perhaps not often in "prolonged, direct physical contact" (in contrast to, say, endosymbionts) and only a subset of humans today are directly involved in farming, strong physical collocation was crucial for the development and evolution of human-domesticate associations in a self-reinforcing manner. This physical collocation made it possible for repeated, long-term interactions within a shared environment and reduced interactions of all partners with other species, allowing their co-evolution as highly involved associations.

Both insect and human crop farmers actively "plant" inocula cultivars and tend to their cultivated species in an ongoing, trans-generational manner. As in human agriculture, insect farmers perform active maintenance and control of community composition, removing "weed" species that would compete with the primary cultivar of interest for nutrients (Batra and Batra 1979). Attine ants perform intensive monitoring of their fungal gardens and remove diseased cultivars with specialized castes to perform distinct tasks (Currie and Stuart 2001); they also manage an intricate web of associations in the ecosystem that include fungal pathogens and associated beneficial bacteria that produce compounds that counter these pathogens (Currie et al. 2003).

Co-evolution and a strong degree of dependency in farming Insect-fungal agricultural systems are exemplars of strong coevolutionary interactions with long evolutionary histories of over 20 million years (Chapela et al. 1994; Mueller et al. 2005). There have been many behavioral and anatomical adaptations of insect hosts and their life cycles to allow the construction, planting, and tending of gardens (Traniello and Leuthold 2000; Bot et al. 2001; Hart et al. 2002; Currie et al. 2006) as well as the (often) vertical 
transmission of cultivar spores when new colonies are founded (Haanstad and Norris 1985; Fernández-Marín et al. 2004). In some cases, the cultivars themselves have evolved to provide nutrition more effectively to their farmers, for example by the growth of nutrient-rich nodules or fungal tip swellings (JRJ and Roeper 1972; Leuthold et al. 1989). For many insect farmers, their dependence on their cultivars is obligate, with cultivars providing the sole source of nutrition for larvae and/or adult insects (Sands 1956; Grassé 1959; Francke-Grosmann 1967; Weber 1972; Mueller et al. 2005). Similarly, the degree of dependence of humans on farmed partners is very high (Larsen 1995; Garibaldi et al. 2011; Granada et al. 2016; Thompson et al. 2020).

The co-evolutionary dynamics in human farm systems is notably characterized by humans that dramatically niche construct and impose strong artificial selection on partner crops and livestock. Although not to the same degree, attine ants also impose some forms of artificial selection to ensure productive and disease-resistant fungal cultivars (Mueller et al. 2004). Human farming has led to the creation of myriad new domesticated species, strains, varieties, and breeds (McCouch 2004; Groeneveld et al. 2010; Brown 2010; Teletchea and Fontaine 2014; Valero et al. 2017; Teletchea 2019). Conversely, there is evidence of genetic change in humans as a consequence of farming (Leach 2003); for example, the ability to digest lactose beyond infancy is associated with pastoralism (Ranciaro et al. 2014) and the ability to digest carbohydrates from marine algae is associated with seaweed farming and consumption (Hehemann et al. 2010).

In general, agriculture and farming can be considered a "ratchet" (Lewis and Maslin 2018). As farming sustains a larger human population (Weisdorf 2005; Gowdy and Krall 2014) and once begun, it must be continued to sustain that population, which in turn nearly always continues to increase. The dependency of humans on any particular crop/animal is usually low to moderate (facultative rather than obligate) since one specific crop may generally be substituted for another, notwithstanding many historical examples of famine due to dependence on monocultures, resource limitations in developing communities, or the cultural importance of particular crops. In insect agriculture by contrast, a particular pairwise relationship is obligate for the farmers. Cultivars are grown as monocultures (Katoh et al. 2002; Aanen et al. 2002) and their removal often causes colony death (Sands 1956; Grassé 1959; Francke-Grosmann 1967; Weber 1972; Mueller et al. 2005). Nevertheless, farmed crops and domesticated animals today are generally highly dependent on human partners: many crops are no longer able to reproduce independently due to genetic changes. For example, staples such as maize and bananas require humans to propagate them and other species such as wheat have been selected for reduced seed dispersal, which facilitates harvesting but likely reduces fitness to live alone with respect to their wild ancestors (Lewis and Maslin
2018). In general, increasing "cultivatability" often leads to a commensurate increase in dependence on humans and the need to be managed, further feeding the farming ratchet as the investment for successful outcomes is increased (Lewis and Maslin 2018). Human dietary changes tied to agricultural practices have led to well-documented reciprocal changes in human genes related to appetite control, metabolic efficiency, and feeding behaviors (Luca et al. 2010).

We suggest that by our definition, both human and insect farming systems can be considered to be symbioses. Striking differences exist between the two, however. While insect agriculture originated multiple times between 20-65 Million years ago (Chapela et al. 1994; Farrell et al. 2001; Aanen et al. 2002), the origins of human farming are a mere 10,000 years ago (Weisdorf 2005). While intricate anatomical adaptations and sequences of behavior have evolved biologically in insect farmers, in human society, equally elaborate farming practices and behaviors are largely cultural and culturally transmitted. The number of human-farmed partnerships is also vast.

Human-domesticate associations share an important feature with many other extant symbioses in allowing the exploitation of new resources and the creation of new niches for the partners involved. These associations divert increasing proportions of primary productivity of ecosystems towards human activities, meeting human needs and appetites, and supporting both human and partner populations (Smil 2011; Williams et al. 2015). This ratchets up an even greater demand for farmed products and farming productivity. This often results in the replacement of extant/wild biomes with anthropogenic biomes ("anthromes" (Ellis et al. 2010)), which is niche construction on a grand scale that often if not always leads to a reduction in biodiversity (Martínez-Ramos et al. 2016; Tilman et al. 2017; Geisen et al. 2019; Sage 2020). Importantly, this self-reinforcing effect on populations and the large-scale habitat changes that accompany farming efforts, are believed to have played a fundamental role in early anthropic transformation of the biosphere and arguably, the start of the Anthropocene (Gowdy and Krall 2013, 2014; Lyons et al. 2016; Boivin et al. 2016). As of 2010, approximately 50\% of all habitable land has been allocated for agriculture (Ellis et al. 2010; Ritchie and Roser 2013; Williams et al. 2015), a figure that is likely to increase as human population increases.

\subsubsection{On fermented foods}

The practice of food fermentation is believed to predate the origins of agriculture (Steinkraus 2004; Sibbesson 2019; Gänzle 2020) although with increased food yields available through farming, fermentation became a traditional method for preserving surplus crops and animal products during hot summer months when food would quickly spoil, and for consumption in winter months when farm yields were low (Campbell-Platt 1987). Like farming, fermentation-or rather 
the interaction of humans and microbial fermentation communities - shares some properties of symbiosis in that elaborate processes of environment creation and manipulation by one partner are used to instantiate and maintain microbial partners and ecological processes to their advantage (Steinkraus 2004; Marshall and Mejía-Lorío 2011; Wiest and Schindler 2011; Wolfe and Dutton 2015; Cosetta and Wolfe 2019). These practices became beneficial to human partners in allowing them to leverage the metabolic abilities of microbes to transform (potential) food sources into products that were easier to preserve and transport, circumvented the energetic demands of cooking, increased the bioavailability of nutrients, reduced toxicity, and were reliably and consistently safe to consume (Marshall and Mejía-Lorío 2011; Chaves-López et al. 2014; Gänzle 2020). Below, we explore whether fermentation-based microbial communities can be considered to be in symbiosis with humans in an evolutionary sense, in reference to our definition of symbiosis articulated in Section 2.1. In particular, we address the criteria of: (i) a shared/co-localized and co-constructed environment, (ii) the transmission of lineages (evolutionary persistence), and (iii) reciprocal co-evolution in the lineages.

\section{Shared environment and transmission of lineages in} fermented foods It has been suggested that the practice of "intentional" fermentation is very ancient, arising approximately 5 million years ago (and thus vastly pre-dating agriculture) and that it may have played an important role in human evolution (Wiest and Schindler 2011). There is evidence to suggest that plant underground storage organs (i.e., "root vegetables"), such as tubers, were added to the early human (Australopithecine) diet (Wrangham 2009). These are useful sources of carbohydrates and other nutrients, but are often toxic unless processed. As fire was not yet in use and there is little archeological evidence of mechanical processing, intentional fermentation is believed to have been used to detoxify these food sources (Wiest and Schindler 2011).

Such early fermentation practices likely exploited surrounding microbial flora and environments in a spontaneous manner rather than the use of propagated inocula or carefully crafted environments to promote fermentation (Steinkraus 2004; Chaves-López et al. 2014; Tamang et al. 2020). The Huron people processed maize by placing ears of corn into stagnant pools with reducing environments (such as marshes) for several months before cooking and consumption (Tooker 1991; Wiest and Schindler 2011) and is an example of the type of simple process that might have been used to render them edible. The strategy of fermenting food for long periods of time in an effort to detoxify it still persists (Steinkraus 1994; Wiest and Schindler 2011), including that of burying Greenland shark (Somniosus microcephalus) meat to produce Icelandic hákarl (Osimani et al. 2019) or fermenting toxic pufferfish ovaries in salted rice-bran paste (Kuda 2015). In this way, fermentation is a means to open up new resources for human sustenance, which has potentially evolutionary consequences.

Fermentation practices and technology have significantly developed and diversified since Neolithic times, including in ways that brought humans into closer association and more extensive interaction with the microbes they now cultivate and propagate. Many culturally codified practices evolved to reliably produce fermented products by constructing effective fermentative niches and developing processes to reproducibly "steer" fermentation towards a desired outcome (CampbellPlatt 1987; Steinkraus 2004; Marshall and Mejía-Lorío 2011). For example, in traditional production of Japanese Koji and derivatives such as sake and doburoku, songs and rhythmic dance movements are used to ensure or precise process timing and very particular physico-sensory cues are used to ensure correct fermentation temperatures or the "doneness" of rice (such as whether cooked rice grains are crushable between finger tips or against a knuckle) (Gekkeikan 1984; Tomoyuki 2018).

As in farming, the practice of fermentation involves the active construction and maintenance of environments (e.g., warmth, darkness) by humans to favor the growth and processes of their desired partners, in this case, beneficial microbial communities. These microbial communities create a characteristically low $\mathrm{pH}$ niche that is often facilitated/co-created by humans through the addition of salt to the starting ferment. As in agriculture, fermentation winnows the biodiversity present to those tolerant of the cultivated conditions (in this case, excluding pathogenic microbes). Depending on the complexity of the fermented product (e.g., cheese, wine, TsukemonoNukazuke pickles, Chinese Baijiu liquor), there may be several steering steps to ensure a properly controlled and cocreated environment for a successful ferment (Hui et al. 2004; Kitamura et al. 2016; Jin et al. 2017; Hutkins 2018). The human drive for fermented products has also led to the construction of physical infrastructures and niches that support their production (e.g., breweries, custom-built cheese caves), arguably in response to the reproducible benefits humans receive from their microbial partners. These built environments may themselves be reservoirs for microbial inocula relevant to the production of the fermented product. Once consumed, the association between microbes resident in the fermented product becomes much more clearly biologically relevant and intimate with human lineages via their gut microbiome. Although vertical transmission of gut microbiota in humans is gaining support (Ferretti et al. 2018; Li et al. 2020), it is unclear at this time if and how fermented products may alter the microbiomes of humans (see below). Nevertheless, microbial cultures handed-down generationally as heirlooms may have led to an entanglement of human and microbial lineages (Ogura 2017; Cook 2018; Flachs and Orkin 2019). 
Co-evolution and a strong degree of dependency in the production of fermented foods Culturally, there has been a strong degree of dependency and integration of microbially fermented foods with human society (Wiest and Schindler 2011; Flachs and Orkin 2019); this is revealed by the diversity and amount of fermented food consumption worldwide, with fermented products accounting for nearly a third of contemporary human diets (Campbell-Platt 1994; Dominy 2015). Most fermentation practices developed and evolved over time to become an ongoing human-microbe association (Cook 2018; Flachs and Orkin 2019). However, has this resulted in co-evolved lineages of fermented food microbiota and humans with identifiable genetic change?

Two general categories of fermentation process exist. In spontaneous, "wild" ferments, the fermentation substrate is left open to colonization by local microbiota from raw materials, the surrounding environment, and/or the humans involved in the process. In deliberate, "inoculated" ferments, a fresh fermentation substrate is seeded with a starter culture from a prior batch, a process sometimes referred to as "backslopping." Back-slopping for many fermented foods has led to the domestication of microbes with clear genetic signatures of artificial selection, particularly those used in industrial scale fermentations (as demonstrated best in the brewer's yeast) (Gibbons and Rinker 2015; Gallone et al. 2016; Steensels et al. 2019). Processes using spontaneous fermentation (mostly non-Western ferments (Tamang et al. 2020)) are often extremely elaborate with clearly evolved cultural processes (e.g., Koji ferments) that reliably provide a specific sequence of selection pressures and carefully controlled ecological successions via the provisioning of different substrates/abiotic conditions over the course of fermentation. Such processes, when carried out repeatedly in the same local environment, give rise to genetically distinct microbial communities that can vary even on small spatial scales such as between villages or even producers (Bokulich et al. 2012; Colehour et al. 2014). Similar to heirloom seeds, many microbial starter cultures selected through many human generations of passage are highly prized, jealously (if not secretly) guarded, and usually have high cultural and commercial value.

As "domesticated" microbiomes, it has been proposed that the microbes associated with traditional fermented foods can be considered as part of an "extended genotype" of humans (Bruessow and Brüssow 2020). However, taking a less human-centric view and given our definition above (Section 2.1), could fermented microbial cultures, like domesticated agricultural organisms, be considered to form a symbiosis with humans? We argue yes, especially for (mostly Western) ferments that use perpetually propagated starter cultures such as beer, yogurt, and cheese (Tamang et al. 2020). Even products generated from spontaneous fermentations carried out repeatedly in a site-specific manner over long periods of time show signs of distinct evolutionary genetic changes in the associated microbes (Gibbons and
Rinker 2015). Ferments that involve contributions from the human skin microbiome (e.g., sourdough bread (Reese et al. 2020)) or oral microbiome (e.g., Latin American chicha beer (Freire et al. 2016)) highlight an even more intimate association with human fermenters.

But is reciprocal co-evolution occurring for humans in response to their association with these microbial ferments? The processing and preservation of raw foods through fermentation is an ancient form of biotechnology and may have modified human evolutionary pressures by promoting a more diverse diet and by buffering volatility in food provisioning and safety of over time and seasonal changes (Katz 2011; Wollstonecroft 2011). By increasing the bioavailability of nutrients from food sources (Gänzle 2020), fermentation may have been instrumental in facilitating the evolution of larger hominid brains at the expense of smaller guts (Cook 1994; Wollstonecroft 2011; Bryant et al. 2020). A recent study by Peters et al. (2019) suggests that a unique type of hydroxycarboxylic acid receptor (HCA3) associated with improved immune, glucose, and insulin functions may have evolved in humans in response to metabolites specifically produced by lactic acid bacteria (e.g., D-phenyllactic acid) very commonly found in fermented foods (Peters et al. 2019). Fermented foods appear to shape our guts at least transiently (Veiga et al. 2014; Derrien and van Hylckama Vlieg 2015; Taylor et al. 2020) although further studies are needed to determine if such changes in host gut microbiota can become persistent with a steady diet of fermented foods (Stiemsma et al. 2020). We know that geographically distinct diets appear to correlate with compositionally distinct human gut microbiome profiles (e.g., see Conteh and Huang 2020), and that Western and Eastern fermented food microbiota are compositionally distinct (Tamang et al. 2020); however, we currently have few data that clearly link causative, coevolved traits of the host or host microbiome with those of humanpassaged microbial ferments. One class of fermented products in particular - alcoholic beverages - has led to a very strong dependency, maintenance, and refinement of microbial cultures that produce these beverages. Although alcoholism is a complex behavioral trait, there is evidence for some evolutionary adaptive changes in certain human lineages in relation to alcohol consumption (Polimanti and Gelernter 2018; Kranzler et al. 2019).

\section{Outlook}

\subsection{A short recap}

We have chosen to operationally define symbiosis as a physical association between two or more organisms that is distinguished by the following 5 key traits: 
1) Symbiotic partners share genetic fates and co-evolve, typically constrained by repeated co-localization if not physical association

2) Symbiotic partners share a uniquely co-created environment for a significant portion of at least one partner's life cycle

3) There is both a degree of dependency and of functional integration between symbiotic partners

4) A holobiont phenotype emerges from the union of symbiotic partners that is distinct and more than the sum of each partner alone

5) Homeostasis is an emergent property of the union of symbiotic partners that tends to maintain the symbiotic association, and is subsequently a trait for selection.

Rapid changes in both biotic and abiotic conditions at both local or global scales have potential impacts on the ecology and evolution of all species including symbiotic associations. We presented a preliminary typology of anthropogenic change (AC) based on a generalization of known accelerating variables that define the Anthropocene. Our typology of AC (Section 3.2) and framework of AC impacts on symbiosis (Section 4.1) are an initial attempt to unpick and systematically operationalize how different types of environmental change might alter different aspects of symbiotic association, with the ultimate aim of helping us to evaluate how AC could affect different ecological and evolutionary processes relevant to symbioses.

The framework we presented attempts to organize and focus on how specific modes of AC impact on symbioses with respect to individual partner fitness and biotic interactions, the holobiont as an emergent entity subject to unique selective pressures, as well as the symbiotic interaction and the uniquely co-created environment that is characteristic of the symbiotic entity. In particular, we emphasized the need to view symbioses with evolutionary principles firmly in mind, and to embrace a "whole-trajectory" perspective, since symbioses can be 'fluid' in both their nature and identity as they bridge the divide between partners-as-individuals and partners-inunion as a new unit of selection. The fluidity of these symbiotic interactions is evidenced by their relational sensitivity to the environment (with respect to the mutualism-parasitism spectrum and the degree of mutual dependency). And yet, symbioses are also often characterized by an emergent homeostasis as partners evolve greater integration (discussed further below in Section 6.2). Together, these features imply that symbioses may be categorically different in their response to $\mathrm{AC}$ than other organisms or ecological interactions.

We discussed how AC could be a force for the destruction of extant symbioses (e.g., nitrogen fertilizers negatively impacting rhizobial-legume symbioses) or their expansion (e.g., ectomycorrhizal-pine invasions), as well as for the creation of new symbioses (e.g., new zoonotic virus associations with humans). Symbioses can be profoundly affected by ACs that lead to dramatic changes in selective pressures and the availability of potential partners; symbioses could, however, be resilient to $\mathrm{AC}$ and new symbioses may come into being as a result of globally changing trends. We provided select case examples (very far from exhaustive) in Section 4.2 on shifts in symbioses in response to AC and musings on the potential for AC-driven symbiogenesis in Section 5, extending our notion of symbiosis to long-term human endeavors like farming. What we have proposed and discussed is a starting point and meant to prompt future discussion. We believe there are at least 3 key questions to be addressed in understanding the impacts of $\mathrm{AC}$ on symbioses that can be drawn out by our conceptualization. Given that symbioses comprise complex sets of biotic-abiotic interactions and the mechanisms to maintain them:

1) What specific types of AC (Section 3.2) are more or less likely to impact symbioses and their evolution?

2) What particular aspects of symbioses (Fig. 2; Section 4.1) are more or less likely to be impacted by a particular type of $A C$ ?

3) Are symbioses more robust/fragile to AC than other types of ecological relationships or individual organisms? If so, why?

Tackling these questions will require a large community effort and the study of many different symbiotic systems to provide enough data to enable generalizations that synthesize insights from these systems as a whole. In Section 6.2, we offer several reflections on the last question above on the robustness of symbiosis to AC. We conclude in Section 6.3 with comments on the centrality of symbioses as ecosystem keystones and a call to action for responsible human engagement in the Anthropocene.

\subsection{On robustness and function}

\subsubsection{Overview}

Implicit in any question about the robustness/fragility of symbiosis to $\mathrm{AC}$ is a requisite accounting of the benefits and tradeoffs of forming a symbiosis (i) relative to being apo- or non-symbiotic and (ii) with respect to before and after $A C$. The fact that symbioses form and persist implies that they must have been sufficiently fit and beneficial (at least to one partner) to have been selected for under a set of "native" conditions, an idea generally consistent with findings from the limited studies on ancestral reconstructions of symbiotic mutualisms (Sachs et al. 2011; Werner et al. 2014; Maherali et al. 2016; Rimington et al. 2019). The difference between these native conditions and new conditions brought about by $\mathrm{AC}$ is a key issue to consider with regards to system robustness. To 
our knowledge, whether symbioses respond differently or uniquely to $\mathrm{AC}$ relative to non-symbiotic ecological interactions remains essentially unexplored in the literature. Before further consideration, however, we review what we know about biological systems, principles of robustness, and the importance of function or processes underlying symbioses.

There are multiple terms - e.g., "robustness," "resilience," "adaptive capacity" - that are used differently across various disciplines to describe the capacity for a system to continue to function or exist in response to perturbation or external change. These concepts overlap to some degree and it may be unhelpful to insist on using one or the other. It is critical, however, to articulate what aspects of the system are to be maintained (i.e., the robustness of what?). In some cases, this may be so obvious that this issue is not explicitly considered or stated; for example, for an individual organism, "robustness" may simply mean that it remains alive or viable in the face of external change. Regardless, there is a need to specify a timescale and scope, e.g., whether one is concerned with the robustness of the organism over one generation or over many generations with respect to persistence of the evolutionary lineage. More complex biological systems involving multiple individual organisms/units of selection require greater conceptual precision. For example, when we consider whether an ecosystem is robust or resilient to environmental change, we need to specify whether we are concerned with the maintenance of particular ecosystem processes and functions or with a specific community composition. Symbioses, as mentioned in Section 2.2, embody aspects of an ecosystem and exist along a continuum from flexible but co-evolved ecological relationships to a higher-level evolutionary individual. What we mean in discussions of what is changing (or not) in the face of AC and how they change may be different across this continuum and thus needs to be stated explicitly.

We believe that the conservation of specific instantiations of symbioses (with specific extant partners) may not be as important as the conservation of the ecological functions, processes, and services of those symbioses. Thus, we concur with Doolittle and Booth's emphasis on the importance of "the song, not the singer" - that it may be more fruitful to cast the "metabolic and developmental interaction patterns" (the song) rather than specific taxa (the singers) of a biological collective as the unit of selection that recapitulates such patterns in subsequent generations under the right conditions (Doolittle and Booth 2017). The proposed typology (Section 3.2) and framework (Section 4) should help in generalizing insights from many different symbiotic case studies, and in focusing conceptually on symbiotic patterns; it can free us from being too concerned with the peculiar details of taxonomy or partner identity in specific symbioses, and shift attention to arguably more important details of process and function. Our discussion of Fig. 2 outlined the need to think of the persistence of symbioses against AC in light of a set of 5 interconnected targets that must be maintained, any of which could be disrupted.

Biological organisms are "complex systems" in the general sense of being made up of extremely heterogeneous components that are organized into a highly structured network with hierarchies and processes that operate at multiple spatial and temporal scales (Carlson and Doyle 2002). Owing to having evolved this sort of complexity, living organisms exhibit a property of "robust-and-fragile": they are robust against some perturbations and fragile to other perturbations, even if small, depending on the structure and feedbacks present within the system (Carlson and Doyle 2002; Kitano and Oda 2006). Feedbacks that develop in complex adaptive systems can be used to maintain system homeostasis in response to common or anticipated perturbations. However, such feedbacks may potentially result in the amplification of small perturbations (often rare or unanticipated) for which the system may not be structured to buffer, which is an unavoidable tradeoff (Carlson and Doyle 2002). Thus, fragility is an intrinsic property for any system composed of biological organisms and the challenge is how to avoid conditions that resonate with such vulnerability.

Broadly speaking, "robustness" refers to the ability of a system to maintain essential functions in the face of external perturbation or change and "resilience" to the capacity of a system to adapt and re-organize in the face of change or perturbation; resilience may also refer to the ability of a system to remain in a given "basin of attraction" of a particular equilibrium state (Resilience Alliance 2010; Capano and Woo 2017; Penn and Barbrook-Johnson 2021). However, robustness and resilience are often used interchangeably, and for our purposes, we are primarily interested in whether a symbiosis can persist by maintaining key patterns of function, process, and dynamics associated with the holobiont in response to $A C$. We describe below how this could occur through redundancy, substitutability, or complementarity of some key functions or components (including partners), active buffering against change (homeostasis), and evolution.

\subsubsection{Robustness through functional and complementary redundancy}

One potential source of robustness comes from having system redundancy or complimentary back-ups of key system components, processes, or functions that provide sufficient internal flexibility or degrees of freedom to respond to a change. This relates in part to Ashby's "law of requisite variety" from cybernetics and the idea that a stable system must have a sufficient number of states to match the number of states that a problem can present (Ashby 1956). Robust systems can essentially 'cover' their weak points by having more components that could compensate should one of those components fail to function. Symbioses are amalgamations of dis-similar 
organisms, joined together by complementarity but also implicit redundancy. The phenomenon of genome reduction in endosymbionts is a consequence of functional redundancy and the notion that duplicative functions will generally be streamlined/trimmed if they do not provide an evolutionary advantage (Delmotte et al. 2006; Moran 2007; Mendonça et al. 2011; Oakeson et al. 2014; Bennett and Moran 2015; Lo et al. 2016). By combining two or more genomes (and depending on the degree of partner dependence and integration), symbioses may be intrinsically redundant in mutually core biological functions that could endow robustness against perturbations that impinge on those functions.

\subsubsection{Robustness through emergent homeostasis}

Symbiotic unions bring not only complementarity and redundancy, but also conflicts and tensions that must be resolved in the coordination of organisms living together and in the negotiation of intrinsic partner self-interests. How these tensions and redundant functions are reconciled with respect to system network, structure, and dynamics to produce homeostasis in the emergent holobiont is precisely the "combinatorial unknown" that makes symbioses a source of evolutionary novelty and open-ended evolution. In addition to the feedback and homeostatic mechanisms that each organismal partner may inherently bring into the symbiosis, new couplings and dynamic responses of partners to one another may instantiate new reciprocal feedbacks in the holobiont system. The coconstruction and maintenance of a shared environment is often an important aspect of emergent homeostasis (Fig. 1B) as well as for how we have defined symbiosis (Section 2.1). In addition to helping to ensure genetic co-variance of partner lineages, spatial co-localization and physical association of symbiotic partners can help buffer against external environmental changes by simple proximity and exclusion. Endosymbiosis provides an extreme example where a partner is housed within the body of another (the host) and buffered from the external environment by the internal environment and homeostatic mechanisms of the host. Mechanisms that maintain a shared environment also provide a measure of buffering against the external environment, and hence environmental change (cf. Prada et al. 2017). This is particularly relevant to types 3-5 in our typology of AC (Section 3.2) concerning changes in mean values or the variability of either local or global environmental variables.

Like a buffer system in chemistry, homeostatic buffering capacity operates over an expanded range of external forcing, but will abruptly transition to a new state and potentially fail if pushed beyond a tipping point, a warning consistently voiced by many climate scientists concerning several Earth systems (Lenton et al. 2008; Heinze et al. 2021). How robust this buffering is to AC, i.e., how much change can be absorbed while still maintaining an environment within the bounds that permit continued functioning or persistence of the symbiosis, will depend on a number of factors. These include: (i) the tolerance range of homeostasis, (ii) the timescales of homeostatic regulation, (iii) how responsive buffering mechanisms are to AC, (iv) the fitness costs associated with maintaining homeostasis under conditions of $\mathrm{AC}$, and (v) the duration of AC.

\subsubsection{Robustness through evolvability}

The ability of random genetic variations to sometimes produce fitness improvements is known as "evolvability" (Wagner and Altenberg 1996) and is a property of all living organisms in response to change. It is generally unclear whether the rates of evolution of partners in symbiosis differ substantively relative to those of organisms in other ecological interactions, although this may depend greatly on the nature of the relationship, relative growth rates, strength of selection, and reproductive barriers (cf. Damore and Gore 2011; Brucker and Bordenstein 2012; Bennett and Moran 2015). There is some evidence suggesting, however, that symbiotic associations of bacterial endophytes with coffee plants may have led to increased rates of plant evolution in response to climactic change (Verstraete et al. 2017; Gillman 2018).

As alluded to above with regards to functional redundancy, the joining of dissimilar organisms in symbiogenesis provides an opportunity for rapid evolutionary innovation through new couplings and combinations of functions encoded by partner genomes, of which metabolic functions may be most important (O'Malley 2015). This sudden burst in "functional repertoire" may enable organisms in early stages of symbiogenesis to be more agile or evolvable with respect to AC (assuming coupling benefits outweigh negative tradeoffs). Evolutionarily 'young' symbioses may also be subject to more intense and dynamic selection pressures as partners initially adapt to a very different life together in a manner that may facilitate more rapid adaptive changes than in 'older,' more wellestablished symbioses (cf. Delmotte et al. 2006; Oakeson et al. 2014). Thus, the evolutionary age of a symbiosis, as well as the degrees of integration and dependence, may pose key constraints on defining the adaptive capacity of symbioses to evolve in response to selective challenges of $\mathrm{AC}$ that impinge on the modes shown in Fig. 2. Unlike homeostasis, which largely deals with transient changes in external conditions, many facets of $\mathrm{AC}$ are about shifting to "new normals" rather than being brief perturbations. Homeostatic mechanisms may buffer against variations experienced by a symbiosis, but new mean values (e.g., temperature) or greater variation in those values (e.g., hotter and colder temperature extremes and/or greater temporal fluctuations) must be dealt with in a chronic fashion, which likely requires evolutionary adaptation. The tension between homeostasis and evolvability, and the underlying differences in process 
timescales for both, need to be considered explicitly in models of AC.

As no organism is an island, the landscape of symbiotic evolution will also be strongly influenced by the biotic filter (mode (III), Section 4), which must be factored into considerations of evolvability. For example, the diversity of partners available, the extent to which some partners are "generalists" vs. "specialists" (see Torres-Martínez et al. 2021), and/or whether such interactions are obligate or facultative will have a major impact on the evolutionary trajectory of a symbiosis. Obligate symbioses may be particularly sensitive to AC given that the extinction of one partner would seal the fate of the other(s) (Mayer et al. 2014) unless new surrogate partners are found. For example, as discussed in Section 5.2, overfertilization is leading to the breakdown of rhizobial-legume crop symbioses, but humans have substituted as the nitrogen provisioning partner for leguminous crop plants (Porter and Sachs 2020). While novel symbioses often lead to range expansion, in general, niche narrowing over time may be expected in obligate, vertically transmitted endosymbionts that can result in fragility with respect to environmental change (Moran 2007; Bennett and Moran 2015).

One might also imagine that obligate mutualisms that are "more open" to environmental variables could be more vulnerable to AC than, for example, those involving endosymbionts in which one partner might shield or buffer the local environment of another through its internal homeostatic mechanisms. A contrasting example is provided by corals: although symbiotic dinoflagellates are endosymbionts of coral tissue, they are unprotected from fluctuating ocean temperatures as the coral host itself generally lacks mechanisms for homeostatic temperature regulation; this can lead to coral bleaching in response to warmer temperatures stemming largely (although not exclusively) from a sensitivity and response of the endosymbionts (Baker et al. 2004; Berkelmans and van Oppen 2006; Sampayo et al. 2008; Weis 2008, 2010; Baird et al. 2009; Cziesielski et al. 2018). For some coral systems, a change in the relative abundance of and dependence on symbiont types within the endosymbiont population in the host can compensate for this temperature fragility (Berkelmans and van Oppen 2006). Coral symbioses are fascinating models for understanding mechanisms for how symbiotic systems could evolve in response to the challenges of AC (Putnam et al. 2017; Stanley and van de Schootbrugge 2018; Blackstone and Golladay 2018; Ying et al. 2018; Weis 2019; Blackstone and Parrin 2020; Buerger et al. 2020; van Oppen and Medina 2020). AC may be inevitable (see below) and efforts that emphasize conserving the functions and ecosystem services ("the song") of coral symbioses may be a more realistic goal than attempting to maintain the specific coral partners ("the singers") observed today. Thus, projects that aim to understand and support the climate resilience of symbiotic systems through human-assisted evolutionary means (e.g., van Oppen et al. 2015; van Oppen et al. 2017) may be better positioned for success in the Anthropocene than contemporary conservation and management efforts focused merely on preserving existing taxa. Symbiotic associations, functions, and ecosystem services with far-reaching impacts on human well-being may be prone to extinction, not just specific taxonomic lineages (Aslan et al. 2013).

Unfortunately, predicting a priori how symbioses could become fragile or sensitive to AC may be incredibly difficult if not impossible. Extant symbioses could provide testable systems for understanding how system redundancy and potential fragility could arise from original, free-living partners, although this would be limited by the degree to which evolutionary and selection histories are known. Regardless, extant symbioses are expected to exhibit robust-and-fragile properties that must simply be studied on a case-by-case basis and analyzed with respect to specific challenges of AC (Section 3.2) before generalization. We believe that a number of fundamental research questions will need to be explored including: (i) under what conditions does symbiotic association (as a life strategy) lead to improved resilience? (ii) how evolvable are different symbioses, and why? and (iii) to what degree are symbiotic associations reversible or canalized and how does this trait impact their evolvability (cf. Bennett and Moran 2015)?

\subsection{Why we should care}

\subsubsection{Symbioses as keystones and its broader impacts}

From the origin of the eukaryotic cell (Margulis 1992; O'Malley 2015) to the evolution and terrestrialization of land plants (Mills et al. 2018; Delaux and Schornack 2021), symbioses have fundamentally shaped the biodiversity and ecosystems of Earth (Gilbert et al. 2012; Guerrero and Berlanga 2016). Symbioses have also provided critical ecosystem services for humans through structural and metabolic innovations that have become quite wide-spread and dominant, e.g., through coral reefs (Woodhead et al. 2019) and rhizobiaassociated leguminous crops and agriculture (de Castro et al. 2016; Stagnari et al. 2017). Given their central role as drivers of ecological and evolutionary change, many symbioses are keystones of ecosystems (Secord 2002; Zook 2002) with the capacity to radically transform biomes, open up and occupy new niches (cf. land plants and corals), and fuel ongoing ecosystem expansion through innovative and hypercompetitive resource utilization (cf. invasive fungal-pine symbioses). We discussed how human-crop/livestock farming represents a class of symbioses sensu lato that may have jump-started the Anthropocene itself and acts as an expanding ratchet. This self-reinforcing nature of human farming underscores intrinsic autocatalytic properties of all symbioses as ecosystem 
engineers, no matter the degree or extent. Given positive feedbacks and the number of symbioses tied to biogeochemical cycles that are considered critical for maintaining safe "planetary boundaries" (Rockström et al. 2009), symbioses should be explicitly included in models of global climate change (cf. Wang et al. 2007; Fisher et al. 2010; Nygren et al. 2012; Reed et al. 2015; Aleixo et al. 2020; He et al. 2021).

Although symbiotic associations are clearly important in the local ecosystems in which they are embedded, the impacts of AC on symbioses can be magnified and ripple out to other domains including social systems. We must be mindful of the interrelationships between biological, economic, policy, and social domains in dealing with global climate change and biodiversity loss, which are intimately linked to issues of land use change and intensification, energy production, global inequality, and economic development. Changes within these domains are often compounded by and interact with each other, and social and economic factors on the Earth system may ultimately be more influential than those biological in origin (Donges et al. 2017). Like many key socio-ecological issues, problems arising from AC are so-called "wicked problems" (Rittel and Webber 1973; Levin et al. 2012; Head and Alford 2015), meaning that: (i) effective interventions are extremely hard to determine a priori, and (ii) there is no single correct solution to the problem given that there are multiple competing human values. Wicked problems cannot be "solved," they can only be navigated and managed, which is the approach we must come to terms with and take to counteract the potential consequences of $A C$.

\subsubsection{The anthropic biosphere is a symbiotic biosphere}

The ubiquity and functional impact of symbioses, both traditionally and more broadly considered, suggests a need to consider symbioses more centrally in the future of the anthropic biosphere. We have advocated the perspective that we must frame questions more generally rather than focus merely on specific case examples, no matter how iconic, in order to more effectively advance symbiosis research vis-à-vis the Anthropocene. Human society is intertwined with symbioses on many scales and these relationships have been crucial in our history as a species. For example, as discussed in Section 5.2, human agriculture both depends on plantmicrobial symbioses and can itself be considered as consisting of higher-level symbioses with humans and specific domesticated crop species as partners. It is likely that many complex ecological and socio-ecological systems have this "Russian doll" or nested character. We exist in a dynamic, multi-scale landscape in which multiple symbioses with biological, human, and cultural components are interacting, declining, forming and evolving simultaneously. Interdisciplinary approaches for dealing with wicked problems from complexity and social sciences are likely worth considering in research efforts aimed at understanding symbioses in an anthropogenically changing world.

The Anthropocene forces us to re-examine our relationships with the "natural world." It is not realistic to maintain a perspective that views us as detached from the Earth's ecosystems, acting merely as custodians or guardians. We have no choice but to "face Gaia" (Latour 2017) and understand that we and the effects of our society are inextricably connected with all ecosystems on Earth today. Less than 3\% of our Earth's ecosystems remain untouched by human influence (Williams et al. 2015; Plumptre et al. 2021) and whether we intend to or not, our choices have and will have profound impacts on the future of Earth's biomes, and through reciprocal feedbacks, our own species. The fact that we have agency (and responsibility) should empower us to take a more active role. There are different paths we could take going forward. Do we focus our interactions with ecosystems towards the preservation of ecosystem services vital to the resilience of human society, the conservation of a "scenic wilderness" that allows our longstanding cultural interactions with ecosystems, to ensure that a particular species will persist, or do we aim to enable extant ecosystems to take on their own evolutionary trajectories into the future wherever that might lead them (Sarrazin and Lecomte 2016)? Will we prioritize 'the song' or 'the singers'? And if the song, which song is it that should be sung?

We believe symbioses are ideal fulcrums for targeted engagement given their keystone nature in ecosystems as described above. Symbiotic associations, even more than keystone species, might be thought of as "ecosystem levers," able to reconfigure or maintain biomes and abiotic environments and thus numerous niches. We have emphasized a functional view of symbiosis as a network of processes and relationships and presented our view that conservation efforts should maintain the biodiversity of functions and processes ("the song") in light of the realities of AC. Just as important, however, is our co-evolutionary, egalitarian view in which no organism is by definition (or implicit bias) the central controlling agent or primary focus of a symbiotic association. The functions and benefits of a symbiosis are distributed across and emerge from the association as a whole. We must move towards a perspective that fully acknowledges that we ourselves are partners embedded in a symbiotic biosphere within which we must act. Moreover, rather than a heavy-handed approach from "the outside," in which we use our enhanced understanding of symbioses as levers to "domineer" the ecosystems around us, we advocate more mindful and subtle approaches to "steer and steward" the anthropic biosphere from within in a manner that will require us to understand, respect, and work with symbioses. How we develop the understanding and the tools to wisely, sustainably, and humbly do this for the benefit of all on Earth is the great challenge of the Anthropocene before us (cf. Ellis et al. 2021). 
Acknowledgements This work is supported in part by National Science Foundation (US) grants \#1541538 (GoLife) and \#1846376 (CAREER) to EFYH and by CECAN: Centre for Evaluation of Complexity Across the Nexus, Economic and Social Research Council (UK) grant \#ES/ N012550/1 and ANTICIPATE: Actively anticipating the unintended consequences on air quality of future public policies, Natural Environment Research Council (UK) grant \#NE/T001739/1 to ASP. EFYH thanks the Deutsches Zentrum für integrative Biodiversitätsforschung (iDiv) of Halle-Jena-Leipzig, Germany (DFGFZT 118, 202548816) for hosting him as a sabbatical visitor during which significant portions of this perspective were written. This is UM Center for Biodiversity Conservation and Research publication No. 027.

Author Contributions Both authors contributed to the conception and writing of this manuscript.

Open Access This article is licensed under a Creative Commons Attribution 4.0 International License, which permits use, sharing, adaptation, distribution and reproduction in any medium or format, as long as you give appropriate credit to the original author(s) and the source, provide a link to the Creative Commons licence, and indicate if changes were made. The images or other third party material in this article are included in the article's Creative Commons licence, unless indicated otherwise in a credit line to the material. If material is not included in the article's Creative Commons licence and your intended use is not permitted by statutory regulation or exceeds the permitted use, you will need to obtain permission directly from the copyright holder. To view a copy of this licence, visit http://creativecommons.org/licenses/by/4.0/.

\section{References}

Aanen DK, Bisseling T (2014) The birth of cooperation. Science 345:2930. https://doi.org/10.1126/science.1256542

Aanen DK, Eggleton P, Rouland-Lefevre C et al (2002) The evolution of fungus-growing termites and their mutualistic fungal symbionts. Proc Natl Acad Sci USA 99:14887-14892. https://doi.org/10. 1073/pnas.222313099

Adams AS, Six DL (2008) Detection of host habitat by parasitoids using cues associated with mycangial fungi of the mountain pine beetle, Dendroctonus ponderosae. Can Entomol 140:124-127. https://doi. org/10.4039/n07-018

Addison A, Powell JA, Bentz BJ, Six DL (2015) Integrating models to investigate critical phenological overlaps in complex ecological interactions: the mountain pine beetle-fungus symbiosis. J Theor Biol 368:55-66. https://doi.org/10.1016/j.jtbi.2014.12.011

Agosta SJ, Klemens JA (2008) Ecological fitting by phenotypically flexible genotypes: implications for species associations, community assembly and evolution. Ecol Lett 11:1123-1134. https://doi.org/ 10.1111/j.1461-0248.2008.01237.x

Alberti M (2015) Eco-evolutionary dynamics in an urbanizing planet. Trends Ecol Evol 30:114-126. https://doi.org/10.1016/j.tree.2014. 11.007

Aleixo S, Gama-Rodrigues AC, Gama-Rodrigues EF et al (2020) Can soil phosphorus availability in tropical forest systems be increased by nitrogen-fixing leguminous trees? Sci Total Environ 712: 136405. https://doi.org/10.1016/j.scitotenv.2019.136405

Allgeier JE, Andskog MA, Hensel E et al (2020) Rewiring coral: anthropogenic nutrients shift diverse coral-symbiont nutrient and carbon interactions toward symbiotic algal dominance. Glob Chang Biol 26:5588-5601. https://doi.org/10.1111/gcb.15230

Altenhoff AM, Studer RA, Robinson-Rechavi M, Dessimoz C (2012) Resolving the ortholog conjecture: orthologs tend to be weakly, but significantly, more similar in function than paralogs. PLoS
Comput Biol 8:e1002514. https://doi.org/10.1371/journal.pcbi. 1002514

Altieri MA (2002) Agroecology: the science of natural resource management for poor farmers in marginal environments. Agric Ecosyst Environ 93:1-24. https://doi.org/10.1016/S0167-8809(02)00085-3

Apprill A (2020) The role of symbioses in the adaptation and stress responses of marine organisms. Ann Rev Mar Sci 12:291-314. https://doi.org/10.1146/annurev-marine-010419-010641

Apprill A (2017) Marine animal microbiomes: toward understanding host-microbiome interactions in a changing ocean. Front Mar Sci 4:222. https://doi.org/10.3389/fmars.2017.00222

Arseneault D, Villeneuve N, Boismenu C et al (1997) Estimating lichen biomass and caribou grazing on the wintering grounds of northern Quebec: an application of fire history and Landsat data. J Appl Ecol 34:65-78. https://doi.org/10.2307/2404848

Ashby WR (1956) An introduction to cybernetics. John Wiley \& Sons, New York

Asin-Garcia E, Kallergi A, Landeweerd L, Martins Dos Santos VAP (2020) Genetic safeguards for safety-by-design: so close yet so far. Trends Biotechnol 38:1308-1312. https://doi.org/10.1016/j.tibtech. 2020.04 .005

Aslan CE, Zavaleta ES, Tershy B, Croll D (2013) Mutualism disruption threatens global plant biodiversity: a systematic review. PLoS One 8:e66993. https://doi.org/10.1371/journal.pone.0066993

Ayalon I, de Barros Marangoni LF, Benichou JIC, et al (2019) Red Sea corals under artificial light pollution at night (ALAN) undergo oxidative stress and photosynthetic impairment. Glob Chang Biol 25: 4194-4207. https://doi.org/10.1111/gcb.14795

Ayalon I, Rosenberg Y, Benichou JIC, et al (2021) Coral gametogenesis collapse under artificial light pollution. Curr Biol 31:413-419.e3. https://doi.org/10.1016/j.cub.2020.10.039

Backer M, Fahselt D (2008) Lichen photobionts and metal toxicity. Symbiosis $46: 1-10$

Baird AH, Bhagooli R, Ralph PJ, Takahashi S (2009) Coral bleaching: the role of the host. Trends Ecol Evol 24:16-20. https://doi.org/10. 1016/j.tree.2008.09.005

Baker AC, Starger CJ, McClanahan TR, Glynn PW (2004) Coral reefs: corals' adaptive response to climate change. Nature 430:741. https:// doi.org/10.1038/430741a

Baker DM, Freeman CJ, Wong JCY et al (2018) Climate change promotes parasitism in a coral symbiosis. ISME J 12:921-930. https:// doi.org/10.1038/s41396-018-0046-8

Barnosky AD, Hadly EA, Bascompte J et al (2012) Approaching a state shift in Earth's biosphere. Nature 486:52-58. https://doi.org/10. 1038/nature11018

Barnosky AD, Matzke N, Tomiya S et al (2011) Has the Earth's sixth mass extinction already arrived? Nature 471:51-57. https://doi.org/ 10.1038/nature09678

Batra LR, Batra SWT (1979) Termite-fungus mutualism. In: Batra LR (ed) Insect-fungus symbiosis: nutrition, mutualism, and commensalism - proceedings of a symposium organized and sponsored by the 2nd International Mycological Congress. Allanheld, Osmun; distributor, Halsted Press, New York, pp 117-163

Beinart RA (2019) The significance of microbial symbionts in ecosystem processes. mSystems 4:e00127-19. https://doi.org/10.1128/ mSystems.00127-19

Bell J, Bianconi G, Butler D et al (2021) Beyond COVID-19: network science and sustainable exit strategies. J Phys Complex 2:021001. https://doi.org/10.1088/2632-072X/abcbea

Bellwood P (2004) First farmers: the origins of agricultural societies, 1st edn. Wiley-Blackwell, Hoboken

Bénard A, Vavre F, Kremer N (2020) Stress \& symbiosis: heads or tails? Front Ecol Evo 8:167. https://doi.org/10.3389/fevo.2020.00167

Benckiser G (2010) Ants and sustainable agriculture. A review. Agron Sustain Dev 30:191-199. https://doi.org/10.1051/agro/2009026 
Bender SF, Wagg C, van der Heijden MGA (2016) An underground revolution: biodiversity and soil ecological engineering for agricultural sustainability. Trends Ecol Evol 31:440-452. https://doi.org/ 10.1016/j.tree.2016.02.016

Bennett GM, Moran NA (2015) Heritable symbiosis: the advantages and perils of an evolutionary rabbit hole. Proc Natl Acad Sci USA 112: 10169-10176. https://doi.org/10.1073/pnas.1421388112

Berkelmans R, van Oppen MJH (2006) The role of zooxanthellae in the thermal tolerance of corals: a "nugget of hope" for coral reefs in an era of climate change. Proc Royal Soc B 273:2305-2312. https:// doi.org/10.1098/rspb.2006.3567

Bernhardt ES, Rosi EJ, Gessner MO (2017) Synthetic chemicals as agents of global change. Front Ecol Environ 15:84-90. https://doi.org/10. $1002 /$ fee. 1450

Betts MG, Wolf C, Pfeifer M et al (2019) Extinction filters mediate the global effects of habitat fragmentation on animals. Science 366: 1236-1239. https://doi.org/10.1126/science.aax9387

Beyer J, Trannum HC, Bakke T et al (2016) Environmental effects of the Deepwater Horizon oil spill: a review. Mar Pollut Bull 110:28-51. https://doi.org/10.1016/j.marpolbul.2016.06.027

Blackall LL, Wilson B, van Oppen MJH (2015) Coral-the world's most diverse symbiotic ecosystem. Mol Ecol 24:5330-5347. https://doi. org/10.1111/mec. 13400

Blackstone NW, Golladay JM (2018) Why do corals bleach? Conflict and conflict mediation in a host/symbiont community. Bioessays 40 : e1800021. https://doi.org/10.1002/bies.201800021

Blackstone NW, Parrin AP (2020) Stress, development, and evolution in coral reef communities. In: Guex J, Torday JS, Miller Jr WB (eds) Morphogenesis, environmental stress and reverse evolution. Springer International Publishing, Cham, pp 233-244. https://doi. org/10.1007/978-3-030-47279-5_11

Blakeslee AMH, McKenzie CH, Darling JA et al (2010) A hitchhiker's guide to the Maritimes: anthropogenic transport facilitates longdistance dispersal of an invasive marine crab to Newfoundland. Divers Distrib 16:879-891. https://doi.org/10.1111/j.1472-4642. 2010.00703.x

Blew RD (1996) On the definition of ecosystem. Bull Ecol Soc Am 77: $171-173$

Bohlool BB, Ladha JK, Garrity DP, George T (1992) Biological nitrogen fixation for sustainable agriculture: a perspective. Plant Soil 141:111. https://doi.org/10.1007/BF00011307

Boivin NL, Zeder MA, Fuller DQ, et al (2016) Ecological consequences of human niche construction: examining long-term anthropogenic shaping of global species distributions. Proc Natl Acad Sci USA 113:6388-6396. https://doi.org/10.1073/pnas.1525200113

Bokulich NA, Bamforth CW, Mills DA (2012) Brewhouse-resident microbiota are responsible for multi-stage fermentation of American coolship ale. PLoS One 7:e35507. https://doi.org/10.1371/journal. pone. 0035507

Bonfante P, Genre A (2010) Mechanisms underlying beneficial plantfungus interactions in mycorrhizal symbiosis. Nat Commun 1:48. https://doi.org/10.1038/ncomms1046

Boone CK, Six DL, Zheng Y, Raffa KF (2008) Parasitoids and dipteran predators exploit volatiles from microbial symbionts to locate bark beetles. Environ Entomol 37:150-161. https://doi.org/10.1093/ee/ 37.1.150

Booth A (2014) Symbiosis, selection, and individuality. Biol Philos 29: 657-673. https://doi.org/10.1007/s10539-014-9449-8

Bot ANM, Currie CR, Hart AG, Boomsma JJ (2001) Waste management in leaf-cutting ants. Ethol Ecol Evol 13:225-237. https://doi.org/10. 1080/08927014.2001.9522772

Bowker MA, Reed SC, Maestre FT, Eldridge DJ (2018) Biocrusts: the living skin of the earth. Plant Soil 429:1-7. https://doi.org/10.1007/ s11104-018-3735-1
Bronstein JL (1994) Conditional outcomes in mutualistic interactions. Trends Ecol Evol 9:214-217. https://doi.org/10.1016/01695347(94)90246-1

Brown AHD (2010) Variation under domestication in plants: 1859 and today. Philos Trans R Soc Lond B Biol Sci 365:2523-2530. https:// doi.org/10.1098/rstb.2010.0006

Brucker RM, Bordenstein SR (2012) Speciation by symbiosis. Trends Ecol Evol 27:443-451. https://doi.org/10.1016/j.tree.2012.03.011

Bruessow F, Brüssow H (2020) Our extended genotype — an argument for the study of domesticated microbes. Environ Microbiol 22: 1669-1674. https://doi.org/10.1111/1462-2920.15001

Brunet MA, Levesque SA, Hunting DJ et al (2018) Recognition of the polycistronic nature of human genes is critical to understanding the genotype-phenotype relationship. Genome Res 28:609-624. https:// doi.org/10.1101/gr.230938.117

Bruno JF, Selig ER, Casey KS et al (2007) Thermal stress and coral cover as drivers of coral disease outbreaks. PLoS Biol 5:e124. https://doi. org/10.1371/journal.pbio.0050124

Bryant K, Hansen C, Hecht E (2020) Fermentation technology as a driver of human brain expansion. Preprints 2020:2020100135. https://doi. org/10.20944/preprints202010.0135.v1

Buck JC, Weinstein SB (2020) The ecological consequences of a pandemic. Biol Lett 16:20200641. https://doi.org/10.1098/rsbl.2020. 0641

Buerger P, Alvarez-Roa C, Coppin CW, et al (2020) Heat-evolved microalgal symbionts increase coral bleaching tolerance. Sci Adv 6:eaba2498. https://doi.org/10.1126/sciadv.aba2498

Campbell-Platt G (1987) Fermented foods of the world. A dictionary and guide. Butterworth-Heinemann, St. Louis

Campbell-Platt G (1994) Fermented foods - a world perspective. Food Res Int 27:253-257. https://doi.org/10.1016/0963-9969(94)90093-0

Canfield DE, Glazer AN, Falkowski PG (2010) The evolution and future of Earth's nitrogen cycle. Science 330:192-196. https://doi.org/10. $1126 /$ science. 1186120

Capano G, Woo JJ (2017) Resilience and robustness in policy design: a critical appraisal. Policy Sci 50:399-426. https://doi.org/10.1007/ s11077-016-9273-x

Carballar-Lejarazú R, Ogaugwu C, Tushar T, et al (2020) Nextgeneration gene drive for population modification of the malaria vector mosquito, Anopheles gambiae. Proc Natl Acad Sci USA 117:22805-22814. https://doi.org/10.1073/pnas.2010214117

Carlson JM, Doyle J (2002) Complexity and robustness. Proc Natl Acad Sci USA 99(Suppl 1):2538-2545. https://doi.org/10.1073/pnas. 012582499

Cavaliere M, Feng S, Soyer OS, Jiménez JI (2017) Cooperation in microbial communities and their biotechnological applications. Environ Microbiol 19:2949-2963. https://doi.org/10.1111/14622920.13767

Cavicchioli R, Ripple WJ, Timmis KN et al (2019) Scientists' warning to humanity: microorganisms and climate change. Nat Rev Microbiol 17:569-586. https://doi.org/10.1038/s41579-019-0222-5

Champer J, Zhao J, Champer SE, et al (2020) Population dynamics of underdominance gene drive systems in continuous space. ACS Synth Biol 9:779-792. https://doi.org/10.1021/acssynbio.9b00452

Chapela IH, Rehner SA, Schultz TR, Mueller UG (1994) Evolutionary history of the symbiosis between fungus-growing ants and their fungi. Science 266:1691-1694. https://doi.org/10.1126/science. 266.5191.1691

Chaves-López C, Serio A, Grande-Tovar CD, et al (2014) Traditional fermented foods and beverages from a microbiological and nutritional perspective: the Colombian heritage. Compr Rev Food Sci Food Saf 13:1031-1048. https://doi.org/10.1111/1541-4337.12098

Chen C, Liu H, Zabad S et al (2021) MoonProt 3.0: an update of the moonlighting proteins database. Nucleic Acids Res 49:D368-D372. https://doi.org/10.1093/nar/gkaa1101 
Cheptou P-O, Hargreaves AL, Bonte D, Jacquemyn H (2017) Adaptation to fragmentation: evolutionary dynamics driven by human influences. Philos Trans R Soc Lond B Biol Sci 372:20160037. https:// doi.org/10.1098/rstb.2016.0037

Chiu CH, Paszkowski U (2020) Receptor-like kinases sustain symbiotic scrutiny. Plant Physiol 182:1597-1612. https://doi.org/10.1104/pp. 19.01341

Clear MR, Hom EFY (2019) The evolution of symbiotic plant-microbe signalling. Annu Plant Rev Online 2:785-836. https://doi.org/10. 1002/9781119312994.apr0684

Colehour AM, Meadow JF, Liebert MA et al (2014) Local domestication of lactic acid bacteria via cassava beer fermentation. PeerJ 2:e479. https://doi.org/10.7717/peerj.479

Coleman-Derr D, Tringe SG (2014) Building the crops of tomorrow: advantages of symbiont-based approaches to improving abiotic stress tolerance. Front Microbiol 5:283. https://doi.org/10.3389/ fmicb.2014.00283

Compant S, van der Heijden MGA, Sessitsch A (2010) Climate change effects on beneficial plant-microorganism interactions. FEMS Microbiol Ecol 73:197-214. https://doi.org/10.1111/j.1574-6941. 2010.00900.x

Conteh AR, Huang R (2020) Targeting the gut microbiota by Asian and Western dietary constituents: a new avenue for diabetes. Toxicol Res 9:569-577. https://doi.org/10.1093/toxres/tfaa065

Conti ME, Cecchetti G (2001) Biological monitoring: lichens as bioindicators of air pollution assessment - a review. Environ Pollut 114:471-492. https://doi.org/10.1016/s0269-7491(00) 00224-4

Cook EE (2018) Human-microbe entanglements. More-than-Human Worlds: a NatureCulture blog series. https://www.natcult.net/ human-microbe-entanglements/

Cook PE (1994) Fermented foods as biotechnological resources. Food Res Int 27:309-316. https://doi.org/10.1016/0963-9969(94)90099-X

Cooper J, Baranski M, Stewart G et al (2016) Shallow non-inversion tillage in organic farming maintains crop yields and increases soil C stocks: a meta-analysis. Agron Sustain Dev 36:22. https://doi.org/ 10.1007/s13593-016-0354-1

Cosetta CM, Wolfe BE (2019) Causes and consequences of biotic interactions within microbiomes. Curr Opin Microbiol 50:35-41. https:// doi.org/10.1016/j.mib.2019.09.004

Cowan NJ, Ankarali MM, Dyhr JP et al (2014) Feedback control as a framework for understanding tradeoffs in biology. Integr Comp Biol 54:223-237. https://doi.org/10.1093/icb/icu050

Crowder LB, Cooper WE (1982) Habitat structural complexity and the interaction between bluegills and their prey. Ecology 63:1802. https://doi.org/10.2307/1940122

Crutzen PJ (2016) Geology of mankind. In: Crutzen PJ, Brauch HG (eds) Paul J. Crutzen: a pioneer on atmospheric chemistry and climate change in the Anthropocene. Springer International Publishing, Cham, pp 211-215. https://doi.org/10.1007/978-3-319-27460-7 10

Csete ME, Doyle JC (2002) Reverse engineering of biological complexity. Science 295:1664-1669. https://doi.org/10.1126/science. 1069981

Currie CR, Bot ANM, Boomsma JJ (2003) Experimental evidence of a tripartite mutualism: bacteria protect ant fungus gardens from specialized parasites. Oikos 101:91-102. https://doi.org/10.1034/j. 1600-0706.2003.12036.x

Currie CR, Poulsen M, Mendenhall J et al (2006) Coevolved crypts and exocrine glands support mutualistic bacteria in fungus-growing ants. Science 311:81-83. https://doi.org/10.1126/science.1119744

Currie CR, Stuart AE (2001) Weeding and grooming of pathogens in agriculture by ants. Proc Biol Sci 268:1033-1039. https://doi.org/ 10.1098/rspb.2001.1605

Cziesielski MJ, Liew YJ, Cui G et al (2018) Multi-omics analysis of thermal stress response in a zooxanthellate cnidarian reveals the importance of associating with thermotolerant symbionts. Proc Biol Sci 285:20172654. https://doi.org/10.1098/rspb.2017.2654

Damore JA, Gore J (2011) A slowly evolving host moves first in symbiotic interactions. Evolution 65:2391-2398. https://doi.org/10.1111/ j.1558-5646.2011.01299.x

Daskin JH, Alford RA (2012) Context-dependent symbioses and their potential roles in wildlife diseases. Proc R Soc B 279:1457-1465. https://doi.org/10.1098/rspb.2011.2276

Das M, Haberer G, Panda A et al (2016) Expression pattern similarities support the prediction of orthologs retaining common functions after gene duplication events. Plant Physiol 171:2343-2357. https://doi. org/10.1104/pp.15.01207

Davy SK, Allemand D, Weis VM (2012) Cell biology of cnidariandinoflagellate symbiosis. Microbiol Mol Biol Rev 76:229-261. https://doi.org/10.1128/MMBR.05014-11

De-Bashan LE, Mayali X, Bebout BM, et al (2016) Establishment of stable synthetic mutualism without co-evolution between microalgae and bacteria demonstrated by mutual transfer of metabolites (NanoSIMS isotopic imaging) and persistent physical association (Fluorescent in situ hybridization). Algal Res 15:179-186. https://doi.org/10.1016/j.algal.2016.02.019

de Castro IV, Fareleira P, Ferreira E (2016) Nitrogen fixing symbiosis in a sustainable agriculture. In: Hakeem KR, Akhtar MS, Abdullah SNA (eds) Plant, soil and microbes. Springer International Publishing, Cham, pp 55-91. https://doi.org/10.1007/978-3-319-27455-3_4

Delaux P-M, Schornack S (2021) Plant evolution driven by interactions with symbiotic and pathogenic microbes. Science 371:eaba6605. https://doi.org/10.1126/science.aba6605

Delmotte F, Rispe C, Schaber J et al (2006) Tempo and mode of early gene loss in endosymbiotic bacteria from insects. BMC Evol Biol 6: 56. https://doi.org/10.1186/1471-2148-6-56

den Herder M, Kytöviita M-M, Niemelä P (2003) Growth of reindeer lichens and effects of reindeer grazing on ground cover vegetation in a Scots pine forest and a subarctic heathland in Finnish Lapland. Ecography 26:3-12. https://doi.org/10.1034/j.1600-0587.2003. 03211.x

Derrien M, van Hylckama Vlieg JET (2015) Fate, activity, and impact of ingested bacteria within the human gut microbiota. Trends Microbiol 23:354-366. https://doi.org/10.1016/j.tim.2015.03.002

Devos Y, Bonsall MB, Firbank LG et al (2020) Gene drive-modified organisms: developing practical risk assessment guidance. Trends Biotechnol in press. https://doi.org/10.1016/j.tibtech.2020.11.015

Didham RK, Tylianakis JM, Hutchison MA et al (2005) Are invasive species the drivers of ecological change? Trends Ecol Evol 20:470 474. https://doi.org/10.1016/j.tree.2005.07.006

Dinerstein E, Joshi AR, Vynne C, et al (2020) A "Global Safety Net" to reverse biodiversity loss and stabilize Earth's climate. Sci Adv 6: eabb2824. https://doi.org/10.1126/sciadv.abb2824

Dominy NJ (2015) Ferment in the family tree. Proc. Natl. Acad. Sci. USA 112:308-309

Donges JF, Winkelmann R, Lucht W, et al (2017) Closing the loop: reconnecting human dynamics to Earth system science. Anthr Rev 4:151-157. https://doi.org/10.1177/2053019617725537

Doolittle WF, Booth A (2017) It's the song, not the singer: an exploration of holobiosis and evolutionary theory. Biol Philos 32:5-24. https:// doi.org/10.1007/s10539-016-9542-2

Doolittle WF, Keeling P, McCutcheon J (2014) Symbioses becoming permanent: the origins and evolutionary trajectories of organelles. http://www.nasonline.org/programs/nas-colloquia/completed colloquia/Symbioses becoming permanent.html

Dorey JE, Hoffman JR, Martino JL, et al (2019) First record of Usnea (Parmeliaceae) growing in New York City in nearly 200 Years. J Torrey Bot Soc 146:69-77. https://doi.org/10.3159/TORREY-D$18-00029.1$

Douglas AE (2010) The symbiotic habit. Princeton University Press, Princeton 
Drigo B, Pijl AS, Duyts H, et al (2010) Shifting carbon flow from roots into associated microbial communities in response to elevated atmospheric $\mathrm{CO}_{2}$. Proc Natl Acad Sci USA 107:10938-10942. https:// doi.org/10.1073/pnas.0912421107

Drury C (2020) Resilience in reef-building corals: the ecological and evolutionary importance of the host response to thermal stress. Mol Ecol 29:448-465. https://doi.org/10.1111/mec.15337

Dunham MJ (2007) Synthetic ecology: a model system for cooperation. Proc. Natl. Acad. Sci. USA 104:1741-1742

Du Z-Y, Zienkiewicz K, Vande Pol N, et al (2019) Algal-fungal symbiosis leads to photosynthetic mycelium. eLife 8:e47815. https://doi. org/10.7554/eLife.47815

Egan S, Gardiner M (2016) Microbial dysbiosis: rethinking disease in marine ecosystems. Front Microbiol 7:991. https://doi.org/10. 3389/fmicb.2016.00991

Ellis EC (2019) Evolution: biodiversity in the Anthropocene. Curr. Biol. 29:R831-R833

Ellis EC, Klein Goldewijk K, Siebert S et al (2010) Anthropogenic transformation of the biomes, 1700 to 2000. Glob Ecol Biogeogr 19:589606. https://doi.org/10.1111/j.1466-8238.2010.00540.x

Ellis EC, Gauthier N, Klein K et al (2021) People have shaped most of terrestrial nature for at least 12000 years. Proc Natl Acad Sci USA 118:e2023483118. https://doi.org/10.1073/pnas.2023483118

Evers CR, Wardropper CB, Branoff B, et al (2018) The ecosystem services and biodiversity of novel ecosystems: a literature review. Glob Ecol Conserv 13:e00362. https://doi.org/10.1016/j.gecco.2017. e00362

Expósito JR, Barreno E, Catalá M (2020) Biological strategies of lichen symbionts to the toxicity of lead $(\mathrm{Pb})$. In: Gupta $\mathrm{DK}$, Chatterjee $\mathrm{S}$, Walther C (eds) Lead in plants and the environment. Springer International Publishing, Cham, pp 149-170. https://doi.org/10. 1007/978-3-030-21638-2 9

Farrell BD, Sequeira AS, O'Meara BC et al (2001) The evolution of agriculture in beetles (Curculionidae: Scolytinae and Platypodinae). Evolution 55:2011-2027. https://doi.org/10.1111/j. 0014-3820.2001.tb01318.x

Fernández-Marín H, Zimmerman JK, Wcislo WT (2004) Ecological traits and evolutionary sequence of nest establishment in fungus-growing ants (Hymenoptera, Formicidae, Attini). Biol J Linn Soc Lond 81: 39-48. https://doi.org/10.1111/j.1095-8312.2004.00268.x

Ferretti P, Pasolli E, Tett A, et al (2018) Mother-to-infant microbial transmission from different body sites shapes the developing infant gut microbiome. Cell Host Microbe 24:133-145.e5. https://doi.org/10. 1016/j.chom.2018.06.005

Fisher JB, Sitch S, Malhi Y et al (2010) Carbon cost of plant nitrogen acquisition: a mechanistic, globally applicable model of plant nitrogen uptake, retranslocation, and fixation. Global Biogeochem Cycles 24:GB1014. https://doi.org/10.1029/2009gb003621

Fitzpatrick SM (2020) Ancient aquaculture and the rise of social complexity. Proc. Natl. Acad. Sci. USA 117:9151-9153

Flachs A, Orkin JD (2019) Fermentation and the ethnobiology of microbial entanglement. Ethnobiol Lett 10:35-39. https://doi.org/10. 14237/ebl.10.1.2019.1481

Foley JA, Defries R, Asner GP et al (2005) Global consequences of land use. Science 309:570-574. https://doi.org/10.1126/science.1111772

Fox JE (2004) Chemical communication threatened by endocrinedisrupting chemicals. Environ Health Perspect 112:648-653. https://doi.org/10.1289/ehp.6455

Fox JE (2005) Non-traditional targets of endocrine disrupting chemicals: the roots of hormone signaling. Integr Comp Biol 45:179-188. https://doi.org/10.1093/icb/45.1.179

Fox JE, Gulledge J, Engelhaupt E et al (2007) Pesticides reduce symbiotic efficiency of nitrogen-fixing rhizobia and host plants. Proc Natl Acad Sci USA 104:10282-10287. https://doi.org/10.1073/pnas. 0611710104
Francke-Grosmann H (1967) Ectosymbiosis in wood-inhabiting insects. In: Henry SM (ed) Symbiosis: associations of invertebrates, birds, ruminants, and other biota: volume II. Academic Press, New York, pp 141-205

Freire AL, Zapata S, Mosquera J, et al (2016) Bacteria associated with human saliva are major microbial components of Ecuadorian indigenous beers (chicha). PeerJ 4:e1962. https://doi.org/10.7717/peerj. 1962

French JRJ, Roeper RA (1972) Interactions of the Ambrosia beetle, Xyleborus dispar (Coleoptera: Scolytidae), with its symbiotic fungus Ambrosiella hartigii (Fungi Imperfecti). Can Entomol 104: 1635-1641. https://doi.org/10.4039/Ent1041635-10

Friedman J, Higgins LM, Gore J (2017) Community structure follows simple assembly rules in microbial microcosms. Nat Ecol Evol 1: 109. https://doi.org/10.1038/s41559-017-0109

Gallaher SD, Craig RJ, Ganesan I et al (2021) Widespread polycistronic gene expression in green algae. Proc Natl Acad Sci USA 118: e2017714118. https://doi.org/10.1073/pnas.2017714118

Gallone B, Steensels J, Prahl T, et al (2016) Domestication and divergence of Saccharomyces cerevisiae beer yeasts. Cell 166:13971410.e16. https://doi.org/10.1016/j.cell.2016.08.020

Gänzle MG (2020) Food fermentations for improved digestibility of plant foods - an essential ex situ digestion step in agricultural societies? Curr Opin Food Sci 32:124-132. https://doi.org/10.1016/j.cofs. 2020.04.002

Garibaldi LA, Aizen MA, Klein AM et al (2011) Global growth and stability of agricultural yield decrease with pollinator dependence. Proc Natl Acad Sci USA 108:5909-5914. https://doi.org/10.1073/ pnas. 1012431108

Geisen S, Wall DH, van der Putten WH (2019) Challenges and opportunities for soil biodiversity in the Anthropocene. Curr Biol 29: R1036-R1044. https://doi.org/10.1016/j.cub.2019.08.007

Gekkeikan (1984) Sake-making work songs: Sakauta, the chant of the sake-makers. https://www.gekkeikan.co.jp/english/history/culture/ worksongs.html. Accessed 23 Mar 2021

Gibbons JG, Rinker DC (2015) The genomics of microbial domestication in the fermented food environment. Curr Opin Genet Dev 35:1-8. https://doi.org/10.1016/j.gde.2015.07.003

Gibb R, Redding DW, Chin KQ et al (2020) Zoonotic host diversity increases in human-dominated ecosystems. Nature 584:398-402. https://doi.org/10.1038/s41586-020-2562-8

Gilbert SF, Sapp J, Tauber AI (2012) A symbiotic view of life: we have never been individuals. Q Rev Biol 87:325-341. https://doi.org/10. $1086 / 668166$

Gilbert SF, Tauber AI (2016) Rethinking individuality: the dialectics of the holobiont. Biol Philos 31:839-853. https://doi.org/10.1007/ s10539-016-9541-3

Gillman S (2018) Could symbiotic microbes help ecosystems survive global warming? Horizon: the EU Research and Innovation Magazine. https://horizon-magazine.eu/article/could-symbioticmicrobes-help-ecosystems-survive-global-warming.html

Gottdenker NL, Streicker DG, Faust CL, Carroll CR (2014) Anthropogenic land use change and infectious diseases: a review of the evidence. EcoHealth 11:619-632. https://doi.org/10.1007/ s10393-014-0941-z

Gowdy J, Krall L (2014) Agriculture as a major evolutionary transition to human ultrasociality. J Bioecon 16:179-202. https://doi.org/10. 1007/s10818-013-9156-6

Gowdy J, Krall L (2013) The ultrasocial origin of the Anthropocene. Ecol Econ 95:137-147. https://doi.org/10.1016/j.ecolecon.2013.08.006

Granada L, Sousa N, Lopes S, Lemos MFL (2016) Is integrated multitrophic aquaculture the solution to the sectors' major challenges? - a review. Rev Aquac 8:283-300. https://doi.org/10. 1111/raq.12093

Grassé PP (1959) Un nouveau type de symbiose: la meule alimentaire des termites champignonnistes. La Nature (Paris) 3293:385-389 
Griffith AW, Gobler CJ (2020) Harmful algal blooms: a climate change co-stressor in marine and freshwater ecosystems. Harmful Algae 91: 101590. https://doi.org/10.1016/j.hal.2019.03.008

Groeneveld LF, Lenstra JA, Eding H et al (2010) Genetic diversity in farm animals - a review. Anim Genet 41(Suppl 1):6-31. https://doi. org/10.1111/j.1365-2052.2010.02038.x

Gronvall GK (2019) Synthetic biology: biosecurity and biosafety implications. In: Singh SK, Kuhn JH (eds) Defense against biological attacks: volume I. Springer International Publishing, Cham, pp 225-232. https://doi.org/10.1007/978-3-030-03053-7_11

Grosskopf T, Soyer OS (2014) Synthetic microbial communities. Curr Opin Microbiol 18:72-77. https://doi.org/10.1016/j.mib.2014.02. 002

Grube M (2010) Die hard: lichens. In: Seckbach J, Grube M (eds) Symbioses and stress: Joint ventures in biology. Springer, Dordrecht, pp 509-523. https://doi.org/10.1007/978-90-481-9449026

Guerrero R, Berlanga M (2016) From the cell to the ecosystem: the physiological evolution of symbiosis. Evol Biol 43:543-552. https://doi.org/10.1007/s11692-015-9360-5

Haanstad JO, Norris DM (1985) Microbial symbiotes of the ambrosia beetle Xyloterinus politus. Microb Ecol 11:267-276. https://doi. org/10.1007/BF02010605

Haase S, Neumann G, Kania A, et al (2007) Elevation of atmospheric $\mathrm{CO}_{2}$ and $\mathrm{N}$-nutritional status modify nodulation, nodule-carbon supply, and root exudation of Phaseolus vulgaris L. Soil Biol Biochem 39:2208-2221. https://doi.org/10.1016/j.soilbio.2007.03.014

Häder D-P, Banaszak AT, Villafañe VE et al (2020) Anthropogenic pollution of aquatic ecosystems: emerging problems with global implications. Sci Total Environ 713:136586. https://doi.org/10.1016/j. scitotenv.2020.136586

Halfwerk W, Slabbekoorn H (2015) Pollution going multimodal: the complex impact of the human-altered sensory environment on animal perception and performance. Biol Lett 11:20141051. https://doi. org/10.1098/rsbl.2014.1051

Hammond TT, Ortiz-Jimenez CA, Smith JE (2020) Anthropogenic change alters ecological relationships via interactive changes in stress physiology and behavior within and among organisms. Integr Comp Biol 60:57-69. https://doi.org/10.1093/icb/icaa001

Han BA, Kramer AM, Drake JM (2016) Global patterns of zoonotic disease in mammals. Trends Parasitol 32:565-577. https://doi.org/ 10.1016/j.pt.2016.04.007

Hansen MC, Potapov PV, Moore R, et al (2013) High-resolution global maps of 21st-Century forest cover change. Science 342:850-853. https://doi.org/10.1126/science. 1244693

Hart AG, Anderson C, Ratnieks FL (2002) Task partitioning in leafcutting ants. Acta Ethol 5:1-11. https://doi.org/10.1007/ s10211-002-0062-5

Head BW, Alford J (2015) Wicked problems: implications for public policy and management. Adm Soc 47:711-739. https://doi.org/10. 1177/0095399713481601

Hehemann J-H, Correc G, Barbeyron T et al (2010) Transfer of carbohydrate-active enzymes from marine bacteria to Japanese gut microbiota. Nature 464:908-912. https://doi.org/10.1038/ nature 08937

He H, Jansson P-E, Gärdenäs AI (2021) CoupModel (v6.0): an ecosystem model for coupled phosphorus, nitrogen, and carbon dynamicsevaluated against empirical data from a climatic and fertility gradient in Sweden. Geosci Model Dev 14:735-761. https://doi.org/10.5194/ gmd-14-735-2021

Heinze C, Blenckner T, Martins $\mathrm{H}$ et al (2021) The quiet crossing of ocean tipping points. Proc Natl Acad Sci USA 118:e2008478118. https://doi.org/10.1073/pnas.2008478118

Henry LP, Fernandez M, Ayroles JF (2020) GxGxE interactions and adaptive potential of the microbiome in Drosophila melanogaster.
bioRxiv 2020.09.21.306779. https://doi.org/10.1101/2020.09.21. 306779

Hill MJ, Southworth J (2016) Anthropogenic change in savannas and associated forest biomes. J Land Use Sci 11:1-6. https://doi.org/ 10.1080/1747423X.2016.1145949

HM Treasury (UK) (2021) Final report - the economics of biodiversity: the Dasgupta review. HM Treasury, UK Government. https://www. gov.uk/government/publications/final-report-the-economics-ofbiodiversity-the-dasgupta-review

Hoadley KD, Lewis AM, Wham DC et al (2019) Host-symbiont combinations dictate the photo-physiological response of reef-building corals to thermal stress. Sci Rep 9:1-15. https://doi.org/10.1038/ s41598-019-46412-4

Hoegh-Guldberg O, Poloczanska ES, Skirving W, Dove S (2017) Coral reef ecosystems under climate change and ocean acidification. Front Mar Sci 4:158. https://doi.org/10.3389/fmars.2017.00158

Hoeksema JD, Averill C, Bhatnagar JM et al (2020) ectomycorrhizal plant-fungal co-invasions as natural experiments for connecting plant and fungal traits to their ecosystem consequences. Front For Glob. Change 3:84. https://doi.org/10.3389/ffgc.2020.00084

Hoeksema JD, Bruna EM (2015) Context-dependent outcomes of mutualistic interactions. In: Bronstein JL (ed) Mutualisms. Oxford University Press, Oxford, pp 181-202

Holbrook SJ, Schmitt RJ, Adam TC, Brooks AJ (2016) Coral reef resilience, tipping points and the strength of herbivory. Sci Rep 6:35817. https://doi.org/10.1038/srep35817

Hölldobler B, Wilson EO (2010) The leafcutter ants: civilization by instinct. W. W. Norton \& Company, New York

Hom EFY, Murray AW (2014) Niche engineering demonstrates a latent capacity for fungal-algal mutualism. Science 345:94-98. https://doi. org/10.1126/science. 1253320

Hosoda K, Seno S, Murakami N et al (2020) A model ecosystem of twelve cryopreservable microbial species allowing for a noninvasive approach. BioRxiv 2020(10):23.351742

Howe-Kerr LI, Bachelot B, Wright RM et al (2020) Symbiont community diversity is more variable in corals that respond poorly to stress. Glob Chang Biol 26:2220-2234. https://doi.org/10.1111/gcb.14999

Howells EJ, Beltran VH, Larsen NW et al (2012) Coral thermal tolerance shaped by local adaptation of photosymbionts. Nat Clim Chang 2: 116-120. https://doi.org/10.1038/nclimate1330

Huang J, Zhang G, Zhang Y et al (2020) Global desertification vulnerability to climate change and human activities. Land Degrad Dev 31: 1380-1391. https://doi.org/10.1002/ldr.3556

Hughes TP, Barnes ML, Bellwood DR et al (2017) Coral reefs in the Anthropocene. Nature 546:82-90. https://doi.org/10.1038/ nature22901

Hui YH, Meunier-Goddik L, Josephsen J et al (eds) (2004) Handbook of food and beverage fermentation technology, 1st edn. Marcel Dekker, New York

Hutkins RW (2018) Microbiology and technology of fermented foods, 2nd edn. Wiley-Blackwell, Hoboken

Ibn-Mohammed T, Mustapha KB, Godsell J et al (2021) A critical analysis of the impacts of COVID-19 on the global economy and ecosystems and opportunities for circular economy strategies. Resour Conserv Recycl 164:105169. https://doi.org/10.1016/j.resconrec. 2020.105169

IPCC AR5 Synthesis Report (2014) Climate Change 2014. Intergovernmental Panel on Climate Change. https://www.ipcc.ch/ report/ar5/syr/

Jansa J, Mozafar A, Kuhn G et al (2003) Soil tillage affects the community structure of mycorrhizal fungi in maize roots. Ecol Appl 13: 1164-1176. https://doi.org/10.1890/1051-0761(2003)13[1164: statcs]2.0.co;2

Janzen DH (1980) When is it coevolution? Evolution 34:611-612. https://doi.org/10.1111/j.1558-5646.1980.tb04849.x 
Janzen DH (1985) On ecological fitting. Oikos 45:308. https://doi.org/10. $2307 / 3565565$

Jeffery CJ (2003) Multifunctional proteins: examples of gene sharing. Ann Med 35:28-35. https://doi.org/10.1080/07853890310004101

Jeon KW (1995) Bacterial endosymbiosis in amoebae. Trends Cell Biol 5:137-140. https://doi.org/10.1016/s0962-8924(00)88966-7

Jeon KW, Lorch IJ (1967) Unusual intra-cellular bacterial infection in large, free-living amoebae. Exp Cell Res 48:236-240. https://doi. org/10.1016/0014-4827(67)90313-8

Jin G, Zhu Y, Xu Y (2017) Mystery behind Chinese liquor fermentation. Trends Food Sci Technol 63:18-28. https://doi.org/10.1016/j.tifs. 2017.02.016

Johnson NC, Angelard C, Sanders IR, Kiers ET (2013) Predicting community and ecosystem outcomes of mycorrhizal responses to global change. Ecol Lett 16(Suppl 1):140-153. https://doi.org/10.1111/ele. 12085

Johnson NC, Graham JH, Smith FA (1997) Functioning of mycorrhizal associations along the mutualism-parasitism continuum. New Phytol 135:575-585. https://doi.org/10.1046/j.1469-8137.1997. 00729.x

Jo I, Fei S, Oswalt CM, et al (2019) Shifts in dominant tree mycorrhizal associations in response to anthropogenic impacts. Sci Adv 5: eaav6358. https://doi.org/10.1126/sciadv.aav6358

Joly K, Chapin FS, Klein DR (2010) Winter habitat selection by caribou in relation to lichen abundance, wildfires, grazing, and landscape characteristics in northwest Alaska. Écoscience 17:321-333. https://doi.org/10.2980/17-3-3337

Joly K, Jandt RR, Klein DR (2009) Decrease of lichens in Arctic ecosystems: the role of wildfire, caribou, reindeer, competition and climate in north-western Alaska. Polar Res 28:433-442. https://doi.org/10. 1111/j.1751-8369.2009.00113.x

Kabir Z (2005) Tillage or no-tillage: impact on mycorrhizae. Can J Plant Sci 85:23-29. https://doi.org/10.4141/p03-160

Kalsotra A, Cooper TA (2011) Functional consequences of developmentally regulated alternative splicing. Nat Rev Genet 12:715-729. https://doi.org/10.1038/nrg3052

Katoh H, Miura T, Maekawa K, et al (2002) Genetic variation of symbiotic fungi cultivated by the macrotermitine termite Odontotermes formosanus (Isoptera: Termitidae) in the Ryukyu Archipelago. Mol Ecol 11:1565-1572. https://doi.org/10.1046/j.1365-294x. 2002.01535x

Katz SE (2011) Fermentation as a co-evolutionary force. In: Cured, smoked, and fermented: Proceedings of the Oxford Symposium on Food and Cookery, 2010. Oxford Symposium, UK

Kawabata Z, Matsui K, Okazaki K et al (1995) Synthesis of a speciesdefined microcosm with protozoa. J Protozool Res 5:23-26

Kazamia E, Riseley AS, Howe CJ, Smith AG (2014) An engineered community approach for industrial cultivation of microalgae. Ind Biotechnol 10:184-190. https://doi.org/10.1089/ind.2013.0041

Keeling PJ, McCutcheon JP (2017) Endosymbiosis: The feeling is not mutual. J Theor Biol 434:75-79. https://doi.org/10.1016/j.jtbi.2017. 06.008

Kehe J, Kulesa A, Ortiz A et al (2019) Massively parallel screening of synthetic microbial communities. Proc Natl Acad Sci U S A 116: 12804-12809. https://doi.org/10.1073/pnas.1900102116

Kelemen O, Convertini P, Zhang Z et al (2013) Function of alternative splicing. Gene 514:1-30. https://doi.org/10.1016/j.gene.2012.07. 083

Kitamura Y, Kusumoto K-I, Oguma T et al (2016) Ethnic fermented foods and alcoholic beverages of Japan. In: Tamang JP (ed) Ethnic fermented foods and alcoholic beverages of Asia. Springer India, New Delhi, pp 193-236. https://doi.org/10.1007/978-81-322-280049

Kitano H, Oda K (2006) Self-extending symbiosis: a mechanism for increasing robustness through evolution. Biol Theory 1:61-66. https://doi.org/10.1162/biot.2006.1.1.61
Klein DR, Shulski M (2011) The role of lichens, reindeer, and climate in ecosystem change on a Bering Sea Island. Arctic 64:353-361

Köhl L, Oehl F, van der Heijden MGA (2014) Agricultural practices indirectly influence plant productivity and ecosystem services through effects on soil biota. Ecol Appl 24:1842-1853. https://doi. org/10.1890/13-1821.1

Kranzler HR, Zhou H, Kember RL et al (2019) Genome-wide association study of alcohol consumption and use disorder in 274,424 individuals from multiple populations. Nat Commun 10:1499. https://doi. org/10.1038/s41467-019-09480-8

Kubo I, Hosoda K, Suzuki S et al (2013) Construction of bacteriaeukaryote synthetic mutualism. Biosystems 113:66-71. https://doi. org/10.1016/j.biosystems.2013.05.006

Kuda T (2015) Quality improvement and fermentation control in fish products. In: Holzapfel W (ed) Advances in fermented foods and beverages. Woodhead Publishing, Cambridge, pp 377-390

Kudela R, Berdalet E, Bernard S et al (2015) Harmful algal blooms: a scientific summary for policy makers. IOC/UNESCO, Paris. https:// unesdoc.unesco.org/ark:/48223/pf0000233419

Kumpula J (2001) Winter grazing of reindeer in woodland lichen pasture: effect of lichen availability on the condition of reindeer. Small Rumin Res 39:121-130. https://doi.org/10.1016/s0921-4488(00) 00179-6

Lambert PM (2009) Health versus fitness: competing themes in the origins and spread of agriculture? Curr Anthropol 50:603-608. https:// doi.org/10.1086/605354

Lanner RM (1996) Made for each other: a symbiosis of birds and pines, 1 st edn. Oxford University Press, New York

Larsen CS (1995) Biological changes in human populations with agriculture. Annu Rev Anthropol 24:185-213. https://doi.org/10.1146/ annurev.an.24.100195.001153

Latour B (2017) Facing Gaia: eight lectures on the new climatic regime. Polity Press, Cambridge

Laurance WF (2010) Habitat destruction: death by a thousand cuts. In: Sodhi NS, Ehrlich PR (eds) Conservation Biology for all. Oxford University Press, New York, pp 73-88

Leach HM (2003) Human domestication reconsidered. Curr Anthropol 44:349-368. https://doi.org/10.1086/368119

Lee JW, Chan CTY, Slomovic S, Collins JJ (2018) Next-generation biocontainment systems for engineered organisms. Nat Chem Biol 14:530-537. https://doi.org/10.1038/s41589-018-0056-x

Lenton TM, Held H, Kriegler E et al (2008) Tipping elements in the Earth's climate system. Proc Natl Acad Sci USA 105:1786-1793. https://doi.org/10.1073/pnas.0705414105

Lesser MP (2011) Coral bleaching: causes and mechanisms. In: Dubinsky Z, Stambler N (eds) Coral reefs: an ecosystem in transition. Springer, Dordrecht, pp 405-419. https://doi.org/10.1007/97894-007-0114-4_23

Leung TLF, Poulin R (2008) Parasitism, commensalism, and mutualism: exploring the many shades of symbioses. Vie et Milieu 58:107-115

Leuthold RH, Badertscher S, Imboden H (1989) The inoculation of newly formed fungus comb with Termitomyces in Macrotermes colonies (Isoptera, Macrotermitinae). Insectes Soc 36:328-338. https://doi. org/10.1007/BF02224884

Levin K, Cashore B, Bernstein S, Auld G (2012) Overcoming the tragedy of super wicked problems: constraining our future selves to ameliorate global climate change. Policy Sci 45:123-152. https://doi.org/ 10.1007/s11077-012-9151-0

Levy O, Fernandes de Barros Marangoni L, Benichou J et al (2020) Artificial light at night (ALAN) alters the physiology and biochemistry of symbiotic reef building corals. Environ Pollut 266:114987. https://doi.org/10.1016/j.envpol.2020.114987

Lewis SL, Maslin MA (2015) Defining the Anthropocene. Nature 519: 171-180. https://doi.org/10.1038/nature14258

Lewis SL, Maslin MA (2018) The human planet: how we created the Anthropocene. Yale University Press, New Haven 
Libby E, Hébert-Dufresne L, Hosseini S-R, Wagner A (2019) Syntrophy emerges spontaneously in complex metabolic systems. PLoS Comput Biol 15:e1007169. https://doi.org/10.1371/journal.pcbi. 1007169

Lidicker WZ Jr (2008) Levels of organization in biology: on the nature and nomenclature of ecology's fourth level. Biol Rev 83:71-78. https://doi.org/10.1111/j.1469-185X.2007.00032.x

Liu J, Yu X, Qin Q et al (2020) The impacts of domestication and breeding on nitrogen fixation symbiosis in legumes. Front Genet 11: 00973. https://doi.org/10.3389/fgene.2020.00973

Li W, Tapiainen T, Brinkac L et al (2020) Vertical transmission of gut microbiome and antimicrobial resistance genes in infants exposed to antibiotics at birth. J Infect Dis, jiaa155. https://doi.org/10.1093/ infdis/jiaa155

Lo W-S, Huang Y-Y, Kuo C-H (2016) Winding paths to simplicity: genome evolution in facultative insect symbionts. FEMS Microbiol Rev 40:855-874. https://doi.org/10.1093/femsre/fuw028

Lozano GL, Bravo JI, Garavito Diago MF, et al (2019) Introducing THOR, a model microbiome for genetic dissection of community behavior. mBio 10:e2846-18. https://doi.org/10.1128/mBio. 02846-18

Luca F, Perry GH, Di Rienzo A (2010) Evolutionary adaptations to dietary changes. Annu Rev Nutr 30:291-314. https://doi.org/10.1146/ annurev-nutr-080508-141048

Lu M, Hulcr J, Sun J (2016) The role of symbiotic microbes in insect invasions. Annu Rev Ecol Evol Syst 47:487-505. https://doi.org/10. 1146/annurev-ecolsys-121415-032050

Lymperopoulou DS, Dobbs FC (2017) Bacterial diversity in ships' ballast water, ballast-water exchange, and implications for ship-mediated dispersal of microorganisms. Environ Sci Technol 51:1962-1972. https://doi.org/10.1021/acs.est.6b03108

Lyons SK, Amatangelo KL, Behrensmeyer AK et al (2016) Holocene shifts in the assembly of plant and animal communities implicate human impacts. Nature 529:80-83. https://doi.org/10.1038/ nature 16447

Maestre FT, Escolar C, de Guevara ML et al (2013) Changes in biocrust cover drive carbon cycle responses to climate change in drylands. Glob Chang Biol 19:3835-3847. https://doi.org/10.1111/gcb.12306

Maherali H, Oberle B, Stevens PF et al (2016) Mutualism persistence and abandonment during the evolution of the mycorrhizal symbiosis. Am Nat 188:E113-E125. https://doi.org/10.1086/688675

Margulis L (1991) Symbiogenesis and symbionticism. In: Margulis L, Fester R (eds) Symbiosis as a source of evolutionary innovation: speciation and morphogenesis. MIT Press, Cambridge, pp 1-14

Margulis L (1992) Symbiosis in cell evolution, 2nd edn. W. H. Freeman, New York

Margulis L, Fester R (eds) (1991) Symbiosis as a source of evolutionary innovation: speciation and morphogenesis. MIT Press, Cambridge

Marshall E, Mejía-Lorío DJ (2011) Traditional fermented food and beverages for improved livelihoods. Rural Infrastructure and AgroIndustries Division, Food and Agriculture Organization of the United Nations, Rome. http://www.fao.org/3/i2477e/i2477e.pdf

Martínez-Ramos M, Ortiz-Rodríguez IA, Piñero D et al (2016) Anthropogenic disturbances jeopardize biodiversity conservation within tropical rainforest reserves. Proc. Natl. Acad. Sci. USA 113:5323-5328

Mayer VE, Frederickson ME, McKey D, Blatrix R (2014) Current issues in the evolutionary ecology of ant-plant symbioses. New Phytol 202:749-764. https://doi.org/10.1111/nph.12690

Maynard Smith J (1989) Evolution: generating novelty by symbiosis. Nature 341:284-285. https://doi.org/10.1038/341284a0

Maynard Smith J, Szathmary E (1997) The major transitions in evolution. Oxford University Press, Oxford

McClanahan TR, Maina JM, Darling ES et al (2020) Large geographic variability in the resistance of corals to thermal stress. Glob Ecol Biogeogr 29:2229-2247. https://doi.org/10.1111/geb.13191
McCouch S (2004) Diversifying selection in plant breeding. PLoS Biol 2: e347. https://doi.org/10.1371/journal.pbio.0020347

McCutcheon JP, Moran NA (2011) Extreme genome reduction in symbiotic bacteria. Nat Rev Microbiol 10:13-26. https://doi.org/10. 1038/nrmicro2670

McFall-Ngai M, Hadfield MG, Bosch TCG et al (2013) Animals in a bacterial world, a new imperative for the life sciences. Proc Natl Acad Sci USA 110:3229-3236. https://doi.org/10.1073/pnas. 1218525110

McFall-Ngai MJ (2014) The importance of microbes in animal development: lessons from the squid-vibrio symbiosis. Annu Rev Microbiol 68:177-194. https://doi.org/10.1146/annurev-micro-091313103654

McMahon TA, Rohr JR, Bernal XE (2017) Light and noise pollution interact to disrupt interspecific interactions. Ecology 98:1290 1299. https://doi.org/10.1002/ecy. 1770

McNeill JR, Engelke P (2016) The Great Acceleration: an environmental history of the Anthropocene since 1945. Belknap Press, Cambridge

Mendonça AG, Alves RJ, Pereira-Leal JB (2011) Loss of genetic redundancy in reductive genome evolution. PLoS Comput Biol 7: e1001082. https://doi.org/10.1371/journal.pcbi.1001082

Merselis DG, Lirman D, Rodriguez-Lanetty M (2018) Symbiotic immuno-suppression: is disease susceptibility the price of bleaching resistance? PeerJ 6:e4494. https://doi.org/10.7717/peerj.4494

Méthot P-O, Alizon S (2014) What is a pathogen? Toward a process view of host-parasite interactions. Virulence 5:775-785. https://doi.org/ 10.4161/21505594.2014.960726

Mickalide H, Kuehn S (2019) Higher-order interaction between species inhibits bacterial invasion of a phototroph-predator microbial community. Cell Syst 9:521-533.e10. https://doi.org/10.1016/j.cels. 2019.11.004

Millennium Ecosystem Assessment (2005) Ecosystems and human wellbeing. WHO Press, Geneva. http://www.bioquest.org/wp-content/ blogs.dir/files/2009/06/ecosystems-and-health.pdf

Mills BJW, Batterman SA, Field KJ (2018) Nutrient acquisition by symbiotic fungi governs Palaeozoic climate transition. Philos Trans R Soc Lond B Biol Sci 373:20160503. https://doi.org/10.1098/rstb. 2016.0503

Mitchell HJ, Bartsch D (2019) Regulation of GM organisms for invasive species control. Front Bioeng Biotechnol 7:454. https://doi.org/10. 3389/fbioe.2019.00454

Moore ML, Six DL (2015) Effects of temperature on growth, sporulation, and competition of mountain pine beetle fungal symbionts. Microb Ecol 70:336-347. https://doi.org/10.1007/s00248-015-0593-8

Moran NA (2007) Symbiosis as an adaptive process and source of phenotypic complexity. Proc Natl Acad Sci USA 104(Suppl 1):86278633. https://doi.org/10.1073/pnas.0611659104

Morris JJ (2018) What is the hologenome concept of evolution? F1000Res 7:1664. https://doi.org/10.12688/f1000research.14385.1

Moya A, Peretó J, Gil R, Latorre A (2008) Learning how to live together: genomic insights into prokaryote-animal symbioses. Nat Rev Genet 9:218-229. https://doi.org/10.1038/nrg2319

Mueller UG, Gerardo NM, Aanen DK, et al (2005) The evolution of agriculture in insects. Annu Rev Ecol Evol Syst 36:563-595. https://doi.org/10.1146/annurev.ecolsys.36.102003.152626

Mueller UG, Poulin J, Adams RMM (2004) Symbiont choice in a fungusgrowing ant (Attini, Formicidae). Behav Ecol 15:357-364. https:// doi.org/10.1093/beheco/arh020

Nash TH (1989) Metal tolerance in lichens. In: Shaw AJ (ed) Heavy metal tolerance in plants: evolutionary aspects. CRC Press, Boca Raton

Nash TH III, Gries C (2002) Lichens as bioindicators of sulfur dioxide. Symbiosis $33: 1-21$

Nguyen PL, van Baalen M (2020) On the difficult evolutionary transition from the free-living lifestyle to obligate symbiosis. PLoS One 15: e0235811. https://doi.org/10.1371/journal.pone.0235811 
Nygren P, Fernández MP, Harmand J-M, Leblanc HA (2012) Symbiotic dinitrogen fixation by trees: an underestimated resource in agroforestry systems? Nutr Cycling Agroecosyst 94:123-160. https://doi. org/10.1007/s10705-012-9542-9

Oakeson KF, Gil R, Clayton AL et al (2014) Genome degeneration and adaptation in a nascent stage of symbiosis. Genome Biol Evol 6:7693. https://doi.org/10.1093/gbe/evt210

Oakley CA, Davy SK (2018) Cell biology of coral bleaching. In: van Oppen MJH, Lough JM (eds) Coral bleaching: patterns, processes, causes and consequences. Springer International Publishing, Cham, pp 189-211. https://doi.org/10.1007/978-3-319-75393-5_8

O'Callaghan M (2016) Microbial inoculation of seed for improved crop performance: issues and opportunities. Appl Microbiol Biotechnol 100:5729-5746. https://doi.org/10.1007/s00253-016-7590-9

Ochman H, Moran NA (2001) Genes lost and genes found: evolution of bacterial pathogenesis and symbiosis. Science 292:1096-1099. https://doi.org/10.1126/science. 1058543

Ogura H (2017) Fermental cultural anthropology (発酵文化人類学: 微生 物からた会のカタチ). Kirakusha, Tokyo

O'Malley MA (2015) Endosymbiosis and its implications for evolutionary theory. Proc Natl Acad Sci USA 112:10270-10277. https://doi. org/10.1073/pnas.1421389112

Osimani A, Ferrocino I, Agnolucci M et al (2019) Unveiling hákarl: a study of the microbiota of the traditional Icelandic fermented fish. Food Microbiol 82:560-572. https://doi.org/10.1016/j.fm.2019.03. 027

Pecl GT, Araújo MB, Bell JD, et al (2017) Biodiversity redistribution under climate change: impacts on ecosystems and human well-being. Science 355:eaai9214. https://doi.org/10.1126/science.aai9214

Pelletier F, Coltman DW (2018) Will human influences on evolutionary dynamics in the wild pervade the Anthropocene? BMC Biol 16:7. https://doi.org/10.1186/s12915-017-0476-1

Penn AS, Barbrook-Johnson P (2021) Understanding the resilience of water, environment and agricultural systems using participatory systems mapping. Socio-Environmental Systems Modelling in press

Peoples MB, Brockwell J, Herridge DF et al (2009) The contributions of nitrogen-fixing crop legumes to the productivity of agricultural systems. Symbiosis 48:1-17. https://doi.org/10.1007/bf03179980

Peters A, Krumbholz P, Jäger E et al (2019) Metabolites of lactic acid bacteria present in fermented foods are highly potent agonists of human hydroxycarboxylic acid receptor 3. PLoS Genet 15: e1008145. https://doi.org/10.1371/journal.pgen.1008145

Phillips N (2021) The coronavirus is here to stay-here's what that means. Nature 590:382-384. https://doi.org/10.1038/d41586-02100396-2

Piatigorsky J (2007) Gene sharing and evolution: the diversity of protein functions. Harvard University Press, Cambridge

Pietrasiak N (2014) Field guide to classify biological soil crusts for ecological site evaluation. USDA-NRCS Technical Reference. https:// www.nrcs.usda.gov/wps/PA NRCSConsumption/download?cid= stelprdb1263524\&ext=pdf

Pietrasiak N, Regus JU, Johansen JR et al (2013) Biological soil crust community types differ in key ecological functions. Soil Biol Biochem 65:168-171. https://doi.org/10.1016/j.soilbio.2013.05.011

Pimm SL, Jenkins CN, Abell R et al (2014) The biodiversity of species and their rates of extinction, distribution, and protection. Science 344:1246752. https://doi.org/10.1126/science.1246752

Plumptre AJ, Baisero D, Belote RT et al (2021) Where might we find ecologically intact communities? Front For Glob Change 4:26. https://doi.org/10.3389/ffgc.2021.626635

Policelli N, Bruns TD, Vilgalys R, Nuñez MA (2019) Suilloid fungi as global drivers of pine invasions. New Phytol 222:714-725. https:// doi.org/10.1111/nph.15660

Polimanti R, Gelernter J (2018) ADH1B: From alcoholism, natural selection, and cancer to the human phenome. Am J Med Genet B
Neuropsychiatr Genet 177:113-125. https://doi.org/10.1002/ajmg. b. 32523

Porter SS, Sachs JL (2020) Agriculture and the disruption of plantmicrobial symbiosis. Trends Ecol Evol 35:426-439. https://doi. org/10.1016/j.tree.2020.01.006

Prada F, Caroselli E, Mengoli S et al (2017) Ocean warming and acidification synergistically increase coral mortality. Sci Rep 7:40842. https://doi.org/10.1038/srep40842

Prescott CE, Grayston SJ, Helmisaari H-S et al (2020) Surplus carbon drives allocation and plant-soil interactions. Trends Ecol Evol 35: 1110-1118. https://doi.org/10.1016/j.tree.2020.08.007

Purvis OW, Halls C (1996) A review of lichens in metal-enriched environments. Lichenologist 28:571-601. https://doi.org/10.1006/lich. 1996.0052

Putnam HM, Barott KL, Ainsworth TD, Gates RD (2017) The vulnerability and resilience of reef-building corals. Curr Biol 27:R528R540. https://doi.org/10.1016/j.cub.2017.04.047

Queller DC (1997) Cooperators since life began. Q Rev Biol 72:184-188. https://doi.org/10.1086/419766

Raman R (2017) The impact of genetically modified (GM) crops in modern agriculture: a review. GM Crops Food 8:195-208. https://doi. org/10.1080/21645698.2017.1413522

Ranciaro A, Campbell MC, Hirbo JB et al (2014) Genetic origins of lactase persistence and the spread of pastoralism in Africa. Am J Hum Genet 94:496-510. https://doi.org/10.1016/j.ajhg.2014.02.009

Ranta P (2001) Changes in urban lichen diversity after a fall in sulphur dioxide levels in the city of Tampere, SW Finland. Ann Bot Fenn 38:295-304

Rassati D, Marini L, Malacrinò A (2019) Acquisition of fungi from the environment modifies ambrosia beetle mycobiome during invasion. PeerJ 7:e8103. https://doi.org/10.7717/peerj.8103

Ravindran S (2016) Inner Workings: Coral reefs at a tipping point. Proc Natl Acad Sci USA 113:5140-5141. https://doi.org/10.1073/pnas. 1605690113

Redman CL (1999) Human impact on ancient environments, 1st edn. University of Arizona Press, Tucson

Redman RS, Rodriguez RJ (2017) The symbiogenic tango: achieving climate-resilient crops via mutualistic plant-fungal relationships. In: Doty SL (ed) Functional importance of the plant microbiome: implications for agriculture, forestry and bioenergy. Springer International Publishing, Cham, pp 71-87. https://doi.org/10.1007/ 978-3-319-65897-1 5

Reed MS, Stringer LC (2016) Land degradation, desertification and climate change: anticipating, assessing and adapting to future change. Routledge, Milton Park

Reed SC, Maestre FT, Ochoa-Hueso R et al (2016) Biocrusts in the context of global change. In: Weber B, Büdel B, Belnap J (eds) Biological soil crusts: an organizing principle in drylands. Springer International Publishing, Cham, pp 451-476. https://doi.org/10. 1007/978-3-319-30214-0 22

Reed SC, Yang X, Thornton PE (2015) Incorporating phosphorus cycling into global modeling efforts: a worthwhile, tractable endeavor. New Phytol 208:324-329. https://doi.org/10.1111/nph.13521

Reese AT, Madden AA, Joossens M, et al (2020) Influences of ingredients and bakers on the bacteria and fungi in sourdough starters and bread. mSphere 5:e0950-19. https://doi.org/10.1128/mSphere. 00950-19

Regus JU, Gano KA, Hollowell AC, et al (2015) Lotus hosts delimit the mutualism-parasitism continuum of Bradyrhizobium. J Evol Biol 28:447-456. https://doi.org/10.1111/jeb.12579

Regus JU, Wendlandt CE, Bantay RM et al (2017) Nitrogen deposition decreases the benefits of symbiosis in a native legume. Plant Soil 414:159-170. https://doi.org/10.1007/s11104-016-3114-8

Resilience Alliance (2010) Assessing resilience in social-ecological systems: Workbook for practitioners, version 2.0. Resilience Alliance. https://www.resalliance.org/files/ResilienceAssessmentV2_2.pdf 
Rhind SM (2009) Anthropogenic pollutants: a threat to ecosystem sustainability? Philos Trans R Soc Lond B Biol Sci 364:3391-3401. https://doi.org/10.1098/rstb.2009.0122

Ribeiro T, Volkery A, Velkavrh AP, et al (2012) Assessment of global megatrends: the European environment - state and outlook 2010. European Environment Agency. http://www.foresight-platform.eu/ wp-content/uploads/2012/11/EFP-Brief-No.-227_Assessment-ofGlobal-Megatrends.pdf

Richardson DHS (1991) Lichens as biological indicators. Recent developments. In: Jeffrey DW, Madden B (eds) Bioindicators and environmental management. Academic Press, New York, pp 263-272

Richardson DHS (1988) Understanding the pollution sensitivity of lichens. Bot J Linn Soc 96:31-43. https://doi.org/10.1111/j.10958339.1988.tb00625.x

Richardson DM, Allsopp N, D'antonio CM et al (2000) Plant invasions - the role of mutualisms. Biol Rev 75:65-93. https://doi. org/10.1111/j.1469-185x.1999.tb00041.x

Richmond RH, Tisthammer KH, Spies NP (2018) The effects of anthropogenic stressors on reproduction and recruitment of corals and reef organisms. Front Mar Sci 5:226. https://doi.org/10.3389/fmars. 2018.00226

Rimington WR, Pressel S, Duckett JG et al (2019) Evolution and networks in ancient and widespread symbioses between Mucoromycotina and liverworts. Mycorrhiza 29:551-565. https:// doi.org/10.1007/s00572-019-00918-x

Ritchie H, Roser M (2013) Land use. https://ourworldindata.org/land-use. Accessed 16 Mar 2021

Rittel HWJ, Webber MM (1973) Dilemmas in a general theory of planning. Policy Sci 4:155-169. https://doi.org/10.1007/BF01405730

Rocha I, Ma Y, Souza-Alonso P et al (2019) Seed coating: a tool for delivering beneficial microbes to agricultural crops. Front Plant Sci 10:1357. https://doi.org/10.3389/fpls.2019.01357

Rockström J, Steffen W, Noone K, et al (2009) Planetary boundaries: exploring the safe operating space for humanity. Ecol Soc 14:32. http://www.ecologyandsociety.org/vol14/iss2/art32/

Rodríguez-Caballero E, Castro AJ, Chamizo S et al (2018) Ecosystem services provided by biocrusts: from ecosystem functions to social values. J Arid Environ 159:45-53. https://doi.org/10.1016/j. jaridenv.2017.09.005

Roosevelt AC (1984) Population, health, and the evolution of subsistence: conclusions from the conference. In: Cohen MN, Armelagos GJ (eds) Paleopathology at the origins of agriculture. Academic Press, New York, pp 559-583

Roossinck MJ (2015) Move over, bacteria! Viruses make their mark as mutualistic microbial symbionts. J Virol 89:6532-6535. https://doi. org/10.1128/JVI.02974-14

Roossinck MJ, Bazán ER (2017) Symbiosis: viruses as intimate partners. Annu Rev Virol 4:123-139. https://doi.org/10.1146/annurevvirology-110615-042323

Rosenberg E, Zilber-Rosenberg I (2018) The hologenome concept of evolution after 10 years. Microbiome 6:78. https://doi.org/10.1186/ s40168-018-0457-9

Rosenberg Y, Doniger T, Levy O (2019) Sustainability of coral reefs are affected by ecological light pollution in the Gulf of Aqaba/Eilat. Commun Biol 2:289. https://doi.org/10.1038/s42003-019-0548-6

Rosenzweig ML (2001) The four questions: what does the introduction of exotic species do to diversity? Evol Ecol Res 3:361-367

Rossi F (2020) Beneficial biofilms for land rehabilitation and fertilization. FEMS Microbiol Lett 367:fnaa184. https://doi.org/10.1093/femsle/ fnaa184

Roughgarden J, Gilbert SF, Rosenberg E et al (2018) Holobionts as units of selection and a model of their population dynamics and evolution. Biol Theory 13:44-65. https://doi.org/10.1007/s13752-017-0287-1

Rouland-Lefèvre C, Bignell DE (2002) Cultivation of symbiotic fungi by termites of the subfamily Macrotermitinae. In: Seckbach J (ed)
Symbiosis: mechanisms and model systems. Springer, Dordrecht, pp 731-756. https://doi.org/10.1007/0-306-48173-1 46

Ruddiman WF (2013) The Anthropocene. Annu Rev Earth Planet Sci 41: 45-68. https://doi.org/10.1146/annurev-earth-050212-123944

Rutz C, Loretto M-C, Bates AE et al (2020) COVID-19 lockdown allows researchers to quantify the effects of human activity on wildlife. Nat Ecol Evol 4:1156-1159. https://doi.org/10.1038/s41559-020-1237-Z

Sachs JL, Skophammer RG, Regus JU (2011) Evolutionary transitions in bacterial symbiosis. Proc Natl Acad Sci USA 108(Suppl 2):10800 10807. https://doi.org/10.1073/pnas.1100304108

Sage RF (2020) Global change biology: a primer. Glob Chang Biol 26:330. https://doi.org/10.1111/gcb.14893

Sampayo EM, Ridgway T, Bongaerts P, Hoegh-Guldberg O (2008) Bleaching susceptibility and mortality of corals are determined by fine-scale differences in symbiont type. Proc Natl Acad Sci USA 105:10444-10449. https://doi.org/10.1073/pnas.0708049105

Sands WA (1956) Some factors affecting the survival of Odontotermes badius. Insectes Sociaux 3:531-536. https://doi.org/10.1007/ BF02226456

Sanz-Saez A, Pérez-López U, Del-Canto A, et al (2019) Changes in environmental $\mathrm{CO}_{2}$ concentration can modify Rhizobium-soybean specificity and condition plant fitness and productivity. Environ Exp Bot 162:133-143. https://doi.org/10.1016/j.envexpbot.2019.01.013

Sarrazin F, Lecomte J (2016) Evolution in the Anthropocene. Science 351:922-923. https://doi.org/10.1126/science.aad6756

Saxena G, Kishor R, Saratale GD, Bharagava RN (2020) Genetically modified organisms (GMOs) and their potential in environmental management: constraints, prospects, and challenges. In: Bharagava RN, Saxena G (eds) Bioremediation of industrial waste for environmental safety. Volume II: Biological agents and methods for industrial waste management. Springer, Singapore, pp 1-19. https://doi. org/10.1007/978-981-13-3426-9_1

Schmidt M, de Lorenzo V (2016) Synthetic bugs on the loose: containment options for deeply engineered (micro)organisms. Curr Opin Biotechnol 38:90-96. https://doi.org/10.1016/j.copbio.2016.01.006

Schultz TR, Mueller UG, Currie CR, Rehner SA (2005) Reciprocal illumination: a comparison of agriculture in humans. In: Vega FE, Blackwell M (eds) Insect-fungal associations: ecology and evolution. Oxford University Press, New York, pp 149-190

Seaward MRD (1992) Large-scale air pollution monitoring using lichens. GeoJournal 28:403-411

Seaward MRD (2004) The use of lichens for environmental impact assessment. Symbiosis 37:293-305

Secord D (2002) Symbioses and their consequences for community and applied ecology. In: Seckbach J (ed) Symbiosis: mechanisms and model systems. Springer, Dordrecht, pp 45-61. https://doi.org/10. 1007/0-306-48173-1 3

Seebens H, Bacher S, Blackburn TM et al (2020) Projecting the continental accumulation of alien species through to 2050. Glob Chang Biol 27:970-982. https://doi.org/10.1111/gcb.15333

Seebens H, Blackburn TM, Dyer EE et al (2017) No saturation in the accumulation of alien species worldwide. Nat Commun 8:14435. https://doi.org/10.1038/ncomms14435

Shapiro JW, Turner PE (2018) Evolution of mutualism from parasitism in experimental virus populations. Evolution 72:707-712. https://doi. org/10.1111/evo. 13440

Shoval O, Sheftel H, Shinar G et al (2012) Evolutionary trade-offs, Pareto optimality, and the geometry of phenotype space. Science 336 : 1157-1160. https://doi.org/10.1126/science.1217405

Showman RE (1997) Continuing lichen recolonization in the upper Ohio River valley. Bryologist 100:478-481. https://doi.org/10.2307/ 3244410

Shu L, Qian X, Brock DA et al (2020) Loss and resiliency of social amoeba symbiosis under simulated warming. Ecol Evol 10: 13182-13189. https://doi.org/10.1002/ece3.6909 
Sibbesson E (2019) Reclaiming the rotten: Understanding food fermentation in the Neolithic and beyond. Environ Archaeol. https://doi. org/10.1080/14614103.2018.1563374

Six DL, Poulsen M, Hansen AK et al (2011) Anthropogenic effects on interaction outcomes: examples from insect-microbial symbioses in forest and savanna ecosystems. Symbiosis 53:101-121. https://doi. org/10.1007/s13199-011-0119-1

Smil V (2011) Harvesting the biosphere: the human impact. Popul Dev Rev 37:613-636. https://doi.org/10.1111/j.1728-4457.2011.00450.x

Smith FA, Smith SE (2013) How useful is the mutualism-parasitism continuum of arbuscular mycorrhizal functioning? Plant Soil 363: 7-18. https://doi.org/10.1007/s11104-012-1583-y

Smith FA, Smith SE (2015) How harmonious are arbuscular mycorrhizal symbioses? Inconsistent concepts reflect different mindsets as well as results. New Phytol 205:1381-1384. https://doi.org/10.1111/nph. 13202

Song H, Ding M-Z, Jia X-Q et al (2014) Synthetic microbial consortia: from systematic analysis to construction and applications. Chem Soc Rev 43:6954-6981. https://doi.org/10.1039/c4cs00114a

Stachowicz JJ (2001) Mutualism, facilitation, and the structure of ecological communities: positive interactions play a critical, but underappreciated, role in ecological communities by reducing physical or biotic stresses in existing habitats and by creating new habitats on which many species depend. Bioscience 51:235-246. https://doi. org/10.1641/0006-3568(2001)051[0235:MFATSO]2.0.CO;2

Stagnari F, Maggio A, Galieni A, Pisante M (2017) Multiple benefits of legumes for agriculture sustainability: an overview. Chem Biol Technol Agric 4:1-13. https://doi.org/10.1186/s40538-016-0085-1

Stanley G, van de Schootbrugge B (2018) The evolution of the coralalgal symbiosis and coral bleaching in the geologic past. In: van Oppen MJH, Lough JM (eds) Coral bleaching: patterns, processes, causes and consequences. Springer International Publishing, Cham, pp 9-26. https://doi.org/10.1007/978-3-319-75393-5_2

Steensels J, Gallone B, Voordeckers K, Verstrepen KJ (2019) Domestication of industrial microbes. Curr Biol 29:R381-R393. https://doi.org/10.1016/j.cub.2019.04.025

Steffen W, Broadgate W, Deutsch L et al (2015a) The trajectory of the Anthropocene: the Great Acceleration. Anthr Rev 2:81-98. https:// doi.org/10.1177/2053019614564785

Steffen W, Crutzen PJ, McNeill JR (2007) The Anthropocene: are humans now overwhelming the great forces of nature. Ambio 36: 614-621. https://doi.org/10.1579/0044-7447(2007)36[614: TAAHNO]2.0.CO;2

Steffen W, Richardson K, Rockström J et al (2020) The emergence and evolution of Earth System Science. Nat Rev Earth Environ 1:54-63. https://doi.org/10.1038/s43017-019-0005-6

Steffen W, Richardson K, Rockström J et al (2015b) Planetary boundaries: guiding human development on a changing planet. Science 347:1259855. https://doi.org/10.1126/science.1259855

Steidinger BS, Crowther TW, Liang J et al (2019) Climatic controls of decomposition drive the global biogeography of forest-tree symbioses. Nature 569:404-408. https://doi.org/10.1038/s41586-019$1128-0$

Steinkraus KH (2004) Origin and history of food fermentations. In: Hui YH, Meunier-Goddik L, Hansen AS et al (eds) Handbook of food and beverage fermentation technology. Marcel Dekkar, New York, pp 1-8

Steinkraus KH (1994) Nutritional significance of fermented foods. Food Res Int 27:259-267. https://doi.org/10.1016/0963-9969(94)90094-9

Steven B, McHugh TA, Reed SC (2017) The response of arid soil communities to climate change. In: Steven B (ed) The biology of arid soils. De Gruyter, Berlin, pp 139-158. https://doi.org/10.1515/ 9783110419047-008

Stiemsma LT, Nakamura RE, Nguyen JG, Michels KB (2020) Does consumption of fermented foods modify the human gut microbiota? J Nutr 150:1680-1692. https://doi.org/10.1093/jn/nxaa077
Stringer LC (2008) Reviewing the international year of deserts and desertification 2006: what contribution towards combating global desertification and implementing the United Nations Convention to Combat Desertification? J Arid Environ 72:2065-2074. https://doi. org/10.1016/j.jaridenv.2008.06.010

Suggett DJ, Smith DJ (2020) Coral bleaching patterns are the outcome of complex biological and environmental networking. Glob Chang Biol 26:68-79. https://doi.org/10.1111/gcb.14871

Sullivan W (2017) Wolbachia, bottled water, and the dark side of symbiosis. Mol Biol Cell 28:2343-2346. https://doi.org/10.1091/mbc. E17-02-0132

Szathmáry E (2015) Toward major evolutionary transitions theory 2.0. Proc Natl Acad Sci USA 112:10104-10111. https://doi.org/10. 1073/pnas. 1421398112

Szathmáry E, Maynard Smith J (1995) The major evolutionary transitions. Nature 374:227-232. https://doi.org/10.1038/374227a0

Szekely P, Sheftel H, Mayo A, Alon U (2013) Evolutionary tradeoffs between economy and effectiveness in biological homeostasis systems. PLoS Comput Biol 9:e1003163. https://doi.org/10.1371/ journal.pcbi.1003163

Tamang JP, Cotter PD, Endo A et al (2020) Fermented foods in a global age: East meets West. Compr Rev Food Sci Food Saf 19:184-217. https://doi.org/10.1111/1541-4337.12520

Tansley AG (1935) The use and abuse of vegetational concepts and terms. Ecology 16:284-307. https://doi.org/10.2307/1930070

Tatem AJ, Hay SI, Rogers DJ (2006) Global traffic and disease vector dispersal. Proc Natl Acad Sci USA 103:6242-6247. https://doi.org/ 10.1073/pnas.0508391103

Taylor BC, Lejzerowicz F, Poirel M, et al (2020) Consumption of fermented foods is associated with systematic differences in the gut microbiome and metabolome. mSystems 5:e00901-19. https:// doi.org/10.1128/mSystems.00901-19

Teletchea F (2019) Animal domestication: a brief overview. In: Teletchea F (ed) Animal domestication. IntechOpen, Rijeka. https://doi.org/ 10.5772/intechopen.86783

Teletchea F, Fontaine P (2014) Levels of domestication in fish: implications for the sustainable future of aquaculture. Fish Fish 15:181195. https://doi.org/10.1111/faf.12006

Thomas VG, Kevan PG (1993) Basic principles of agroecology and sustainable agriculture. J Agric Environ Ethics 6:1-19. https://doi.org/ 10.1007/BF01965612

Thompson JN (2005) The geographic mosaic of coevolution. University of Chicago Press, Chicago

Thompson JN (2009) The coevolving web of life. Am Nat 173:125-140. https://doi.org/10.1086/595752

Thompson JN (2013) Relentless evolution. University of Chicago Press, Chicago

Thompson JN (2014) Interaction and Coevolution. University of Chicago Press, Chicago

Thompson VD, Marquardt WH, Savarese M et al (2020) Ancient engineering of fish capture and storage in southwest Florida. Proc Natl Acad Sci USA 117:8374-8381. https://doi.org/10.1073/pnas. 1921708117

Tilman AR, Plotkin JB, Akçay E (2020) Evolutionary games with environmental feedbacks. Nat Commun 11:915. https://doi.org/10.1038/ s41467-020-14531-6

Tilman D (2004) Niche tradeoffs, neutrality, and community structure: a stochastic theory of resource competition, invasion, and community assembly. Proc Natl Acad Sci USA 101:10854-10861. https://doi. org/10.1073/pnas.0403458101

Tilman D, Clark M, Williams DR et al (2017) Future threats to biodiversity and pathways to their prevention. Nature 546:73-81. https://doi. org/10.1038/nature22900

Tolleter D, Seneca FO, DeNofrio JC et al (2013) Coral bleaching independent of photosynthetic activity. Curr Biol 23:1782-1786. https:// doi.org/10.1016/j.cub.2013.07.041 
Tomoyuki NM (2018) Personal communication, Alexandra Penn (Tokyo)

Tooker E (1991) An ethnography of the Huron Indians, 1615-1649. Syracuse University Press, Syracuse

Torjesen I (2021) Covid-19 will become endemic but with decreased potency over time, scientists believe. BMJ 372:n494. https://doi. org/10.1136/bmj.n494

Torres-Martínez L, Porter SS, Wendlandt CE et al (2021) Evolution of specialization in a plant-microbial mutualism is explained by the oscillation theory of speciation. Evolution 75:1070-1086. https:// doi.org/10.1111/evo.14222

Traniello JFA, Leuthold RH (2000) Behavior and ecology of foraging in termites. In: Abe T, Bignell DE, Higashi M (eds) Termites: evolution, sociality, symbioses, ecology. Springer, Dordrecht, pp 141168. https://doi.org/10.1007/978-94-017-3223-9_7

UNDP Human Development Report (2020) The next frontier: human development and the Anthropocene. United Nations Development Programme. http://report.hdr.undp.org/

Valero M, Guillemin M-L, Destombe C et al (2017) Perspectives on domestication research for sustainable seaweed aquaculture. Perspect Phycol 4:33-46. https://doi.org/10.1127/pip/2017/0066

van Baalen M, Jansen VAA (2001) Dangerous liaisons: the ecology of private interest and common good. Oikos 95:211-224. https://doi. org/10.1034/j.1600-0706.2001.950203.x

van Oppen MJH, Medina M (2020) Coral evolutionary responses to microbial symbioses. Philos Trans R Soc Lond B Biol Sci 375: 20190591. https://doi.org/10.1098/rstb.2019.0591

van Oppen MJH, Gates RD, Blackall LL et al (2017) Shifting paradigms in restoration of the world's coral reefs. Glob Chang Biol 23:34373448. https://doi.org/10.1111/gcb.13647

van Oppen MJH, Oliver JK, Putnam HM, Gates RD (2015) Building coral reef resilience through assisted evolution. Proc Natl Acad Sci USA 112:2307-2313. https://doi.org/10.1073/pnas.1422301112

Vázquez MM, César S, Azcón R, Barea JM (2000) Interactions between arbuscular mycorrhizal fungi and other microbial inoculants (Azospirillum, Pseudomonas, Trichoderma) and their effects on microbial population and enzyme activities in the rhizosphere of maize plants. Appl Soil Ecol 15:261-272. https://doi.org/10.1016/S09291393(00)00075-5

Veiga P, Pons N, Agrawal A et al (2014) Changes of the human gut microbiome induced by a fermented milk product. Sci Rep 4: 6328. https://doi.org/10.1038/srep06328

Verstraete B, Janssens S, Rønsted N (2017) Non-nodulated bacterial leaf symbiosis promotes the evolutionary success of its host plants in the coffee family (Rubiaceae). Mol Phylogenet Evol 113:161-168. https://doi.org/10.1016/j.ympev.2017.05.022

Vesala R, Harjuntausta A, Hakkarainen A et al (2019) Termite mound architecture regulates nest temperature and correlates with species identities of symbiotic fungi. PeerJ 6:e6237. https://doi.org/10.7717/ peerj.6237

Vitousek PM, Aber JD, Howarth RW, et al (1997) Human alteration of the global nitrogen cycle: sources and consequences. Ecol Appl 7: 737-750. https://doi.org/10.1890/1051-0761(1997)007[0737: haotgn]2.0.co;2

Wagg C, Veiga R, van der Heijden MGA (2015) Facilitation and antagonism in mycorrhizal networks. In: Horton TR (ed) Mycorrhizal networks. Springer, Dordrecht, pp 203-226. https://doi.org/10. 1007/978-94-017-7395-9 7

Wagner GP, Altenberg L (1996) Complex adaptations and the evolution of evolvability. Evolution 50:967-976. https://doi.org/10.2307/ 2410639

Wang Y-P, Houlton BZ, Field CB (2007) A model of biogeochemical cycles of carbon, nitrogen, and phosphorus including symbiotic nitrogen fixation and phosphatase production: a biogeochemical model of C, N, and P. Global Biogeochem Cycles 21:GB1018. https:// doi.org/10.1029/2006GB002797
Watson JEM, Jones KR, Fuller RA et al (2016) Persistent disparities between recent rates of habitat conversion and protection and implications for future global conservation targets: protected areas and habitat conversion. Conserv Lett 9:413-421. https://doi.org/10. $1111 /$ conl.12295

Weber NA (1972) Gardening ants, the attines. Memoirs of the American Philosophical Society, Volume 92. American Philosophical Society, Philadelphia

Wedell N, Price TAR, Lindholm AK (2019) Gene drive: progress and prospects. Proc Biol Sci 286:20192709. https://doi.org/10.1098/ rspb.2019.2709

Wein T, Romero Picazo D, Blow F et al (2019) Currency, exchange, and inheritance in the evolution of symbiosis. Trends Microbiol 27:836 849. https://doi.org/10.1016/j.tim.2019.05.010

Weisdorf JL (2005) From foraging to farming: explaining the Neolithic revolution. J Econ Surv 19:561-586. https://doi.org/10.1111/j.09500804.2005.00259.x

Weis VM (2008) Cellular mechanisms of Cnidarian bleaching: stress causes the collapse of symbiosis. J Exp Biol 211:3059-3066. https://doi.org/10.1242/jeb.009597

Weis VM (2010) The susceptibility and resilience of corals to thermal stress: adaptation, acclimatization or both? Mol. Ecol. 19:15151517 https://doi.org/10.1111/j.1365-294X.2010.04575.x.

Weis VM (2019) Cell biology of coral symbiosis: foundational study can inform solutions to the coral reef crisis. Integr Comp Biol 59:845855. https://doi.org/10.1093/icb/icz067

Werner GDA, Cornwell WK, Sprent JI, et al (2014) A single evolutionary innovation drives the deep evolution of symbiotic $\mathrm{N}_{2}$-fixation in angiosperms. Nat Commun 5:4087. https://doi.org/10.1038/ ncomms 5087

Wiest M, Schindler B (2011) Remembering lessons from the past: fermentation and the restructuring of our food system. In: Cured, smoked, and fermented: Proceedings of the Oxford Symposium on Food and Cookery, 2010. Oxford Symposium, UK

Williams M, Zalasiewicz J, Haff PK et al (2015) The Anthropocene biosphere. Anthr Rev 2:196-219. https://doi.org/10.1177/ 2053019615591020

Willis A, Rodrigues BF, Harris PJC (2013) The ecology of arbuscular mycorrhizal fungi. CRC Crit Rev Plant Sci 32:1-20. https://doi.org/ 10.1080/07352689.2012.683375

Wilson JRU, Dormontt EE, Prentis PJ et al (2009) Something in the way you move: dispersal pathways affect invasion success. Trends Ecol Evol 24:136-144. https://doi.org/10.1016/j.tree.2008.10.007

Wolfe BE, Dutton RJ (2015) Fermented foods as experimentally tractable microbial ecosystems. Cell 161:49-55. https://doi.org/10.1016/j. cell.2015.02.034

Wollstonecroft MM (2011) Investigating the role of food processing in human evolution: a niche construction approach. Archaeol Anthropol Sci 3:141-150. https://doi.org/10.1007/s12520-0110062-3

Woodhead AJ, Hicks CC, Norström AV et al (2019) Coral reef ecosystem services in the Anthropocene. Funct Ecol 33:1023-1034. https://doi.org/10.1111/1365-2435.13331

Wrangham R (2009) Catching fire: how cooking made us human, 1st edn. Basic Books, New York

Ying H, Cooke I, Sprungala S et al (2018) Comparative genomics reveals the distinct evolutionary trajectories of the robust and complex coral lineages. Genome Biol 19:175. https://doi.org/10.1186/s13059-018$1552-8$

Zalasiewicz J, Williams M, Smith A et al (2008) Are we now living in the Anthropocene. GSA Today 18:4. https://doi.org/10.1130/ gsat01802a.1

Zhao L, Lu M, Niu H et al (2013) A native fungal symbiont facilitates the prevalence and development of an invasive pathogen-native vector symbiosis. Ecology 94:2817-2826. https://doi.org/10.1890/122229.1 
Zomorrodi AR, Segrè D (2016) Synthetic ecology of microbes: mathematical models and applications. J Mol Biol 428:837-861. https:// doi.org/10.1016/j.jmb.2015.10.019

Zook DP (2002) Prioritizing symbiosis to sustain biodiversity: are symbionts keystone species? In: Seckbach J (ed) Symbiosis: mechanisms and model systems. Springer, Dordrecht, pp 3-12. https:// doi.org/10.1007/0-306-48173-1_1
Zug R, Hammerstein P (2015) Bad guys turned nice? A critical assessment of Wolbachia mutualisms in arthropod hosts. Biol Rev 90:89111. https://doi.org/10.1111/brv.12098

Publisher's note Springer Nature remains neutral with regard to jurisdictional claims in published maps and institutional affiliations. 